\title{
Investigation of Temperature and Aging Effects in Nanostructured Dye Solar Cells Studied by Electrochemical Impedance Spectroscopy
}

\author{
Minna Toivola, Janne Halme, Lauri Peltokorpi, and Peter Lund \\ Department of Applied Physics, Advanced Energy Systems, Helsinki University of Technology, P.O. Box 5100, 02015 TKK, Finland \\ Correspondence should be addressed to Minna Toivola, mjktoivo@cc.hut.fi
}

Received 17 November 2008; Revised 28 May 2009; Accepted 6 August 2009

Recommended by A. Hagfeldt

Effects of aging and cyclically varying temperature on the electrical parameters of dye solar cells were analyzed with electrochemical impedance spectroscopy. Photoelectrode total resistance increased as a function of time due to increasing electron transport resistance in the $\mathrm{TiO}_{2}$ film. On the other hand, photoelectrode recombination resistance was generally larger, electron lifetimes in the $\mathrm{TiO}_{2}$ were film longer, and charge transfer resistance on the counter electrode was smaller after the temperature treatments than before them. These effects correlated with the slower deterioration rate of the temperature-treated cells, in comparison to the reference cells.

Copyright () 2009 Minna Toivola et al. This is an open access article distributed under the Creative Commons Attribution License, which permits unrestricted use, distribution, and reproduction in any medium, provided the original work is properly cited.

\section{Introduction}

Nanostructured, dye-sensitized titanium dioxide solar cell (DSC) [1] is a promising, easily manufacturable, and lowcost alternative to the conventional silicon and thin film photovoltaic devices. The highest reported energy conversion efficiencies exceed already 10\% [2-4] but the long-term stability of the cells and the effects of varying environmental conditions on them during their operation still require more detailed investigation before this technology can fully compete against the more traditional and established solar electricity solutions.

Compared to the amount of publications on the development of new cell materials or manufacturing methods, relatively few have concentrated on the cell aging or the effects of temperature, air humidity, or other environmental conditions on the cell performance (e.g., [5-23]). Also, in many cases the cell function has been characterized mainly by IV-curve measurements. Electrochemical impedance spectroscopy (EIS) is, however, another well-established and effective method to probe deeper the fundamental charge transfer phenomena in the cell components (e.g., [24-37]). Wang et al., for example, have used EIS to identify the origins of changes induced by thermal aging on the DSC performance [22]. They found that thermal stress decreased the electron lifetimes in the $\mathrm{TiO}_{2}$ film, while improvement in the counter electrode performance was detected during the first few days of aging. Similar behavior was observed also by Kern et al. [23], that is, decrease in the electron lifetimes but no degradation in the counter electrode catalyst during thermal aging of the cells.

The objective of this study was to gain more profound understanding and verify some previous observations about the DSC's temperature behavior and aging-induced changes on it. Understanding the temperature behavior of the DSC performance has significant practical importance because in real life applications the cells are often subjected to even drastic changes in temperature, for example, if the modules are placed on a rooftop and the temporal variation in the ambient temperature is large. In our previous research it was noticed that repeatedly and regularly varying temperature had a regenerative effect on both the photo- and counter electrode functions in the aged DSCs [38]. In [38] cell performance was monitored as a function of time with IVcurve measurements while the cell temperature was varied in regular to-and-fro ramps and EIS was used to investigate the charge transfer on the electrodes before and after every temperature ramping, while keeping the cells at constant 
room temperature. In the present study, the cell operating temperature was varied in ramps $20^{\circ} \mathrm{C} \rightarrow 40^{\circ} \mathrm{C} \rightarrow 70^{\circ} \mathrm{C} \rightarrow$ $40^{\circ} \mathrm{C} \rightarrow 20^{\circ} \mathrm{C}$, and the EIS spectra were measured at all aforementioned temperatures from fresh, 11-12 days, 29 days, and 76-78 days, aged cells, after which an extensive analysis of the evolution of the impedance parameters with time and temperature was performed. To follow the temporal behavior of the overall cell performance, IV-curve measurements were also employed before and after every temperature ramping.

Because temperature affects the open circuit voltage of the cell, another set of temperature-ramped EIS measurements was performed later, where the cell voltage was controlled and fixed by external polarization. This removed the temperature-induced variation from the voltage and enabled better analysis of the temperature behavior of the impedance parameters, such as charge transfer resistance and capacitance of the electrodes.

\section{Experimental}

2.1. Cell Preparation. Dye solar cell photoelectrodes were prepared on conducting glass substrates (Pilkington TEC15 , thickness $2.5 \mathrm{~mm}$, sheet resistance $15 \Omega /$ sq., supplied by Hartford Glass Company, Inc.) with doctor-blading method from $20 \mathrm{wt} \%$ suspension of $\mathrm{TiO}_{2}$ nanoparticles (P25, Degussa) in ethanol. Three layers of the suspension were spread and compressed in a hydraulic press (125$250 \mathrm{~kg} / \mathrm{cm}^{2}$ ) to improve the interparticle contacts and adherence to the substrate. After this half of the electrodes was sintered in $500^{\circ} \mathrm{C}$ for 30 minutes, another half was left nonsintered. The size of the substrates was $16 \mathrm{~mm} \times 20 \mathrm{~mm}$, the electrode active area $0.32 \mathrm{~cm}^{2}(4 \mathrm{~mm} \times 8 \mathrm{~mm})$, and the electrode thickness $12-14 \mu \mathrm{m}$. Sensitization of the electrode films was done by soaking them in $0.32 \mathrm{mM}$ solution of the $\mathrm{N}-719$ dye (cis-bis (isothiocyanato)bis $\left(2,2^{\prime}\right.$-bipyridyl-4, $4^{\prime}$ dicarboxylato)-ruthenium(II) bis-tetrabutylammonium, Solaronix SA) in absolute ethanol for ca. 70 hours. Long sensitization time was used to ensure uniform and thorough adsorption of the dye.

Platinized glass counter electrodes prepared with the standard thermal platinization method, as described previously [39], were employed in all cells.

The electrodes were sealed together on a hot plate $\left(100^{\circ} \mathrm{C}\right)$ using $50 \mu \mathrm{m}$ thick Surlyn 1702 thermoplastic polymer film as a spacer and sealant, and finally the cells were filled with either liquid or semisolid (gel) electrolyte. The composition of the liquid electrolyte was $0.5 \mathrm{M}$ LiI, $0.05 \mathrm{M} \mathrm{I}_{2}$, and $0.5 \mathrm{M}$ 4-tert-butylpyridine (TBP) in 3-methoxypropionitrile. The semisolid electrolyte was made of the liquid by gelatinizing it with $5 \mathrm{wt} \%$ of PVDF-HFP (polyvinylidenefluoride-hexafluoropropylene), a method described in literature [40]. Table 1 summarizes the cell types prepared for this study.

2.2. Measurements. EIS spectra were recorded with Zahner Elektrik's IM6 Impedance Measurement Unit operated with Thales software and using a red LED of wavelength $640 \mathrm{~nm}$
TABLe 1: Cell types.

\begin{tabular}{lcc}
\hline Cell series & Sintered photoelectrode & Electrolyte \\
\hline L-S & Yes & Liquid \\
G-S & Yes & Gel \\
L-NS & No & Liquid \\
G-NS & No & Gel \\
\hline
\end{tabular}

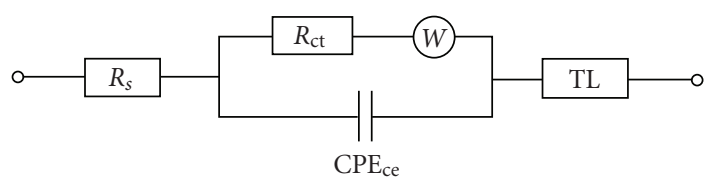

FIGURE 1: Equivalent circuit used for the EIS spectra fits. $R_{s}$ : series resistance of the cell. TL : transmission line element, as introduced by Bisquert, Fabregat-Santiago et al. (e.g., [24]), modeling the photoelectrode and including the photoelectrode resistance $R_{\mathrm{pe}}$ (consisting of the electron diffusion resistance in the $\mathrm{TiO}_{2}$ film $\left(R_{\mathrm{tr}}\right)$ and the recombination resistance on the $\mathrm{TiO}_{2}$-dye-electrolyte interface $\left(R_{\mathrm{rec}}\right)$ : i.e., $\left.R_{\mathrm{pe}}=R_{\mathrm{rec}}+R_{\mathrm{tr}}\right)$ and the constant phase element $\mathrm{CPE}_{\mathrm{pe}}$, describing the capacitance of the $\mathrm{TiO}_{2}$ film surface. $R_{\mathrm{ct}}$ : charge transfer resistance on the counter electrode-electrolyte interface. $\mathrm{CPE}_{\mathrm{ce}}$ : constant phase element describing the counter electrode capacitance. $W$ : Warburg element associated with the diffusion in the electrolyte. Constant phase elements were used instead of pure capacitances because they describe better a realistic, uneven, and unhomogenous electrode surface [41].

and illumination intensity ca. $8 \%$ of the 1 sun irradiance (meaning, the photocurrent measured from the cell being ca. $8 \%$ of what the cell would give under one sun illumination) as the light source. In the first set of measurements, the spectra were obtained at open circuit voltage with $10 \mathrm{mV}$ voltage amplitude in the $100 \mathrm{mHz}-100 \mathrm{kHz}$ frequency range, first at $20^{\circ} \mathrm{C}$, then at $40^{\circ} \mathrm{C}$ and $70^{\circ} \mathrm{C}$, after which the temperature was lowered and the spectra obtained again at $40^{\circ} \mathrm{C}$ and $20^{\circ} \mathrm{C}$. Cell heating/cooling was arranged by placing the measurement box with the cells and the LED on a hot plate with internal temperature control by Pt-1000 temperature sensors. Before every measurement, the cells were let to stabilize at a given temperature for 10 minutes. The accuracy of the temperature control was $\pm 2-4^{\circ} \mathrm{C}$. ZPlot/ZView software from Scribner Inc. was used for equivalent circuit fits of the EIS spectra. Figure 1 describes the model circuit used in the fits.

IV-curves were measured at $20^{\circ} \mathrm{C}$ before and after every temperature ramping with a custom-built solar simulator consisting of ten $150 \mathrm{~W}$ halogen lamps as the light source, a temperature-controlled measurement plate, and a calibrated monocrystalline silicon reference cell with which the lamps could be adjusted to provide the standard light intensity of $100 \mathrm{~mW} / \mathrm{cm}^{2}$. The spectral mismatch factor of the simulator, defined by the reference cell and the measured spectral irradiance of the halogen lamps, was used to make the curves correspond with the standard AM1.5G equivalent illumination. A few cells of each series were chosen as reference cells which were let to age at constant temperature 
in the dark. Their EIS spectra and IV-curves were measured on the same days with the temperature-treated cells.

All measurements described above were performed with fresh, 11-12 days, 29 days (one month), and 76-78 days (two and half months), aged cells. Between the measurements, the cells were stored in dark and at room temperature (22$24^{\circ} \mathrm{C}$ ) to provide controlled aging conditions. Aging in the dark was chosen because of the preliminary nature of the experiments and to distinguish between the changes on the cell performance caused by constant light soaking.

The second set of EIS measurements was performed with the sintered cells (three liquid and three gel electrolyte filled cells), on one day only, ca. three months after the last measurements of the first set (the cells were in good, even condition, and their efficiencies still over $4 \%$ which validated their use even this long after their preparation). Measurement parameters were the same as in the first set, but instead of obtaining the spectra at open circuit voltage, external bias voltage of $-0.6 \mathrm{~V},-0.65 \mathrm{~V},-0.7 \mathrm{~V}$, and $-0.75 \mathrm{~V}$ was applied on the cell. Temperature rampings similar to the first set of measurements were performed at every polarization and the EIS spectra obtained at all temperatures. From here on, the terms "first set" and "second set" are used to distinguish between these two types of EIS measurements.

\section{Results and Discussion}

3.1. IV-Curves. The aging and temperature behavior of the IV-curves was very similar for all cell types, as also found in the previous study [38]. The only differences were the relatively higher short circuit currents and efficiencies obtained with sintered and liquid electrolyte filled cells in comparison to nonsintered and gel electrolyte cells. This is known to be due to better $\mathrm{TiO}_{2}$ film quality (interparticle connections and adhesion to the substrate) in sintered electrodes and better penetration of the liquid electrolyte into the pores of the $\mathrm{TiO}_{2}$ layer.

The most striking feature in all temperature-treated cells was improvement of their efficiencies during the first couple of weeks of aging. This was due to increased open circuit voltages and was observed with both temperature-treated and reference cells. As depicted in Figure 2 and Supplementary Table 2 (See Supplementary Material available online at doi: $10.1155 / 2009 / 786929$.) , the steepest voltage increases happened in the first temperature rampings on day 1 after which only very small rise or none at all could be observed. Similar behavior was observed also with the reference cells, indicating that even if the temperature treatments might have worked in favor of this effect, they cannot be held fully responsible of it. For the reference cells, the relative voltage increase evened out with time also and was the largest between the first two consecutive measurement days, causing a simultaneous gain in efficiencies for the most of the cell series.

The exact explanation for the open circuit voltage increase remains still open but despite of the long dyesensitization time, it can be assumed that the final equilibrium between the dye, TBP, and other molecules adsorbed on the $\mathrm{TiO}_{2}$ film surface was not yet reached when the first measurements were performed. Thus it is possible that there were, for example, excess dye molecules only poorly attached to the film still left during the first measurements and their desorption with time (possibly favored by the temperature treatments) made adsorption possible for larger amounts of the other electrolyte species. As TBP is known to increase the open circuit voltage [28], larger amount of it on the film surface could at least partially explain this behavior. However, verification of this kind of assumptions calls for different analysis techniques than IV-curve or EIS measurements only and was outside the scope of this study.

Despite the decreasing overall trend in short circuit currents over time, the currents either remained the same or increased, that is, were regenerated during the temperature rampings, in most cases both for the fresh and aged cells. This was also responsible for the relatively slower degradation of the sintered and temperature-treated cells when compared to the reference cells in these series. Deterioration in the sintered and temperature-treated cells' performance was not observed until the last measurements on days 77-78. For the non-sintered cells the $V_{\mathrm{oc}}$ increase contributed so much to the evolution of the cell performance over time, also with the reference cells, that their efficiency behavior was the opposite to the sintered cells, that is, percentually smaller efficiency degradation for the reference cells during the observation period (Supplementary Table 3). However, as it can be seen from Figure 2 and Supplementary Table 2, the general trend was that the temperature treatments led to regeneration of the short circuit current also for these cell series. In general, the short circuit current regeneration was relatively larger for the gel electrolyte-filled cells. This is most likely due to the lower viscosity of the gel in higher temperatures, which improves the gel's penetration into the pores of the $\mathrm{TiO}_{2}$ film and its contact with the $\mathrm{TiO}_{2}$ nanoparticles. As an irreversible effect this can affect the current generation still when the temperature is lowered again.

\subsection{EIS Measurements}

3.2.1. General Trends in the EIS Spectra. Three arcs and three imaginary impedance peaks can usually be detected in the Nyquist and Bode plots, respectively, of the impedance spectra of dye solar cells [22-24]. The high-frequency arc $(\mathrm{kHz}$ region) can be associated with the charge transfer on the counter electrode $\left(R_{\mathrm{ct}}|| \mathrm{CPE}_{\mathrm{ce}}\right.$ in Figure 1$)$. The middle frequency arc $(\mathrm{ca} .10 \mathrm{~Hz})$ describes the photoelectrode impedance $\left(R_{\mathrm{tr}}-R_{\mathrm{rec}} \| \mathrm{CPE}_{\mathrm{pe}}\right.$ corresponds, in Figure 1, to the transmission line element TL [24]), where the components of the photoelectrode total resistance $R_{\mathrm{pe}}$ are the charge transfer resistance for recombination of the $\mathrm{TiO}_{2}$ conduction band and/or trap state electrons with the electrolyte species $\left(R_{\mathrm{rec}}\right)$ and the transport resistance of the electrons in the $\mathrm{TiO}_{2}$ film $\left(R_{\mathrm{tr}}\right)$. The low-frequency arc ( $\mathrm{mHz}$ region) is associated with the ionic diffusion in the electrolyte (component $W$ in Figure 1), but in our measurements, the diffusion arc was either fused with or almost completely masked by the photoelectrode impedance, which is why it was left out of the equivalent circuit fits as well. Figures 3 and 4 present 

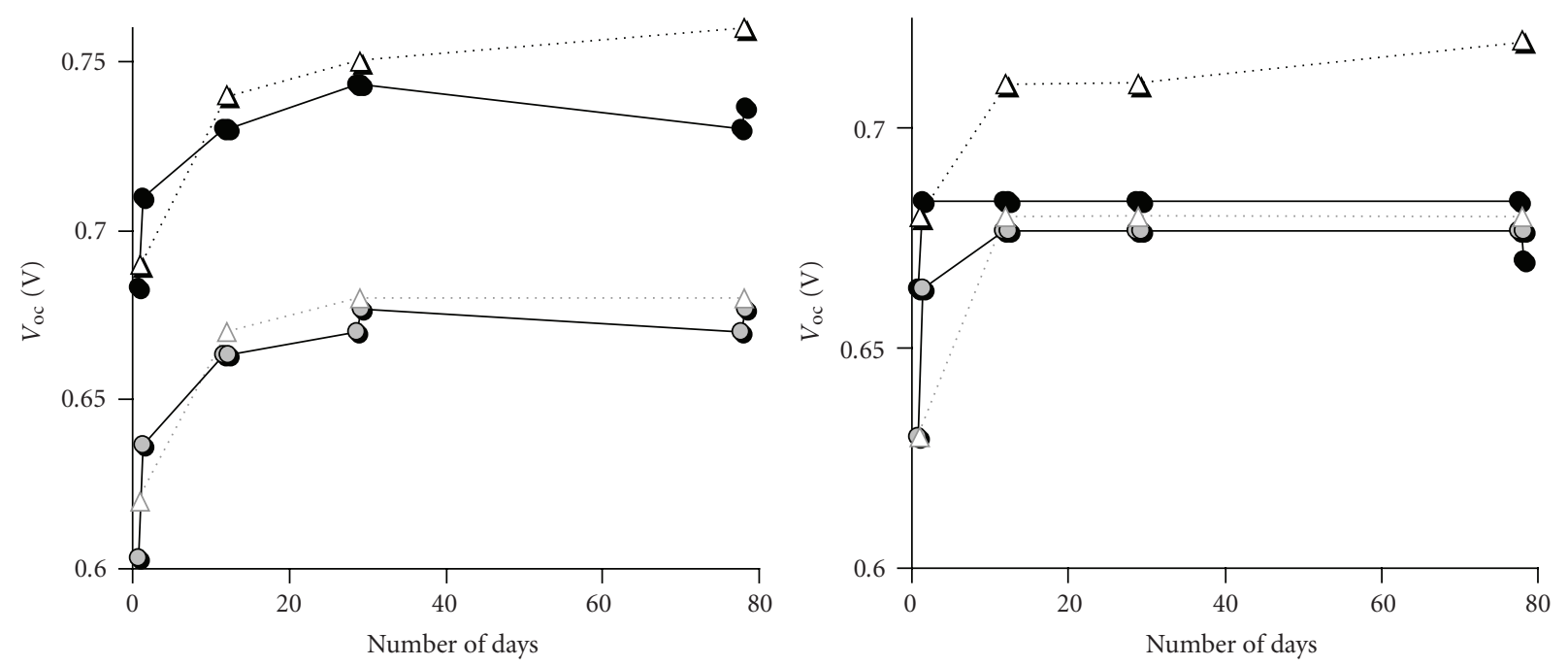

(a)
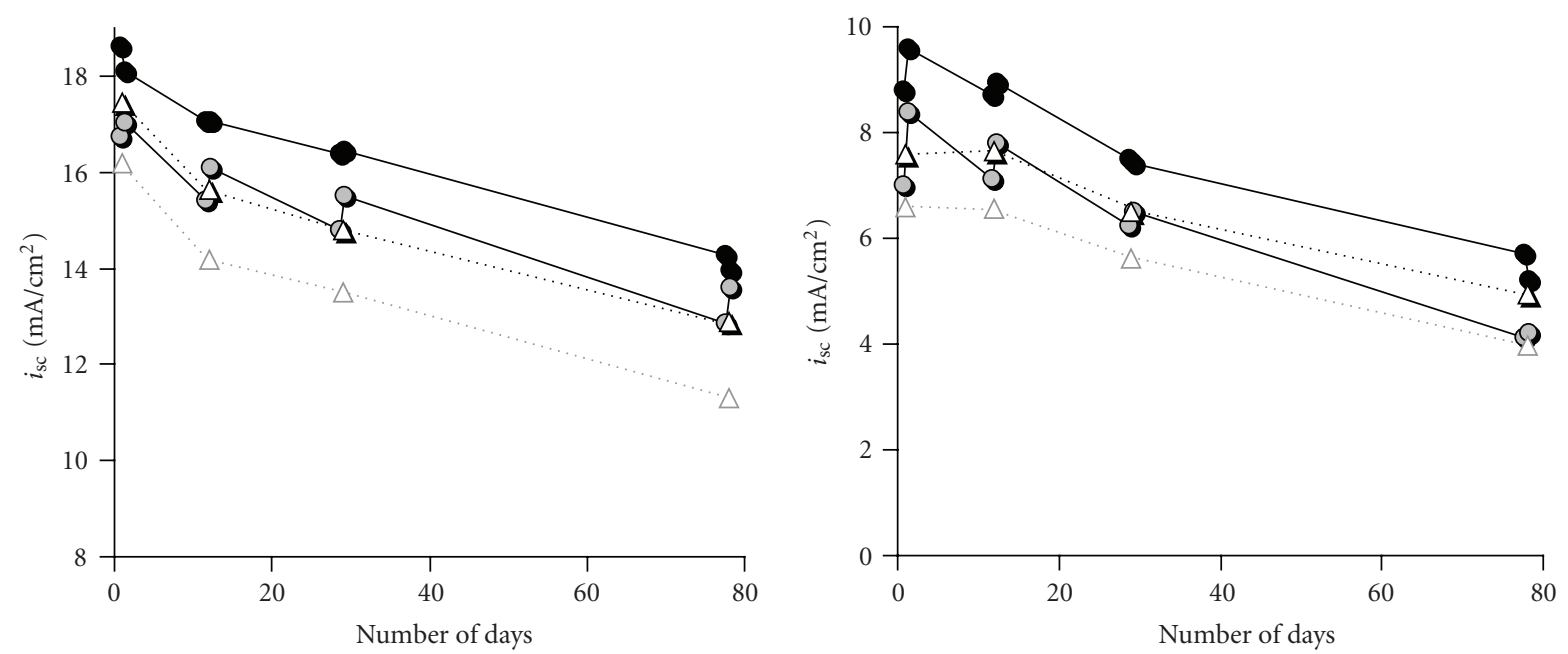

(b)
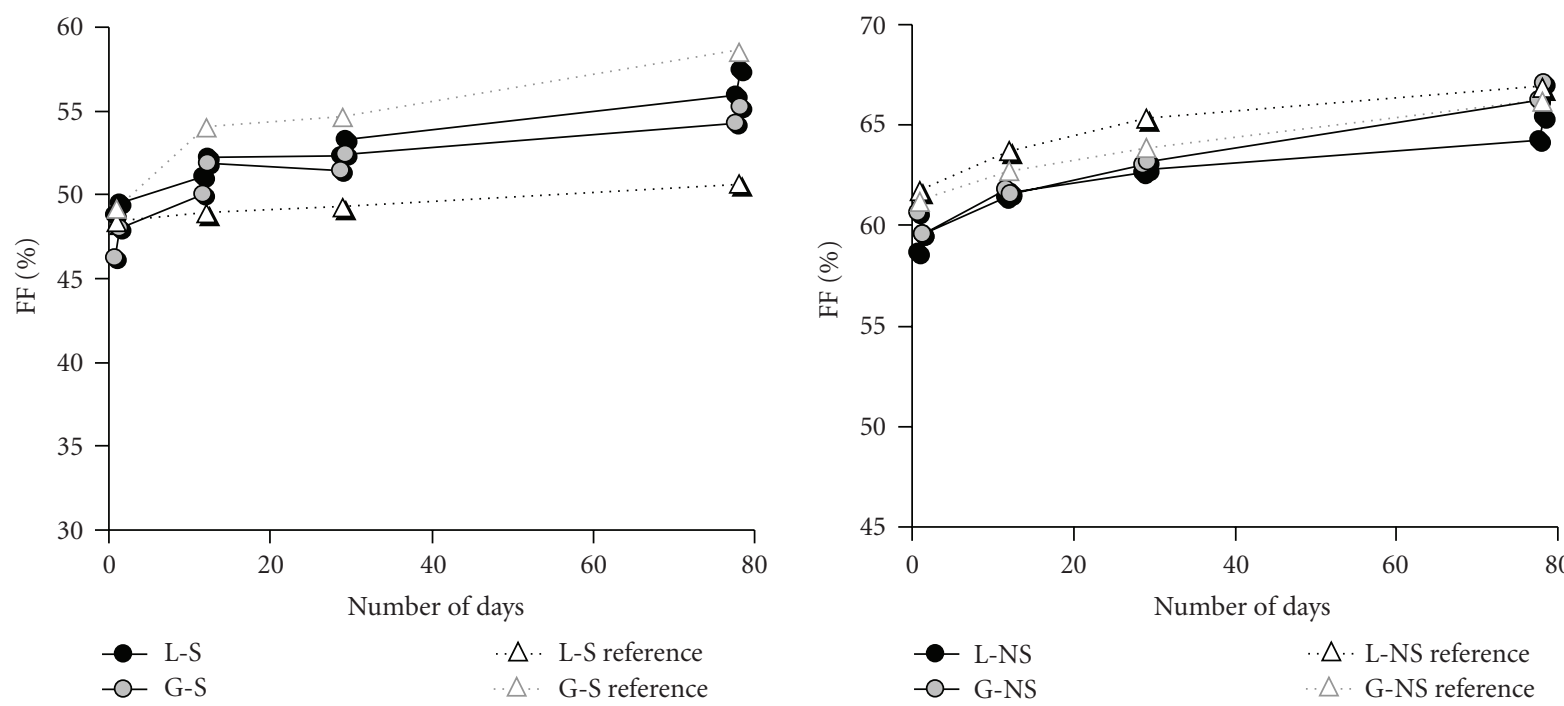

(c)

Figure 2: Continued. 

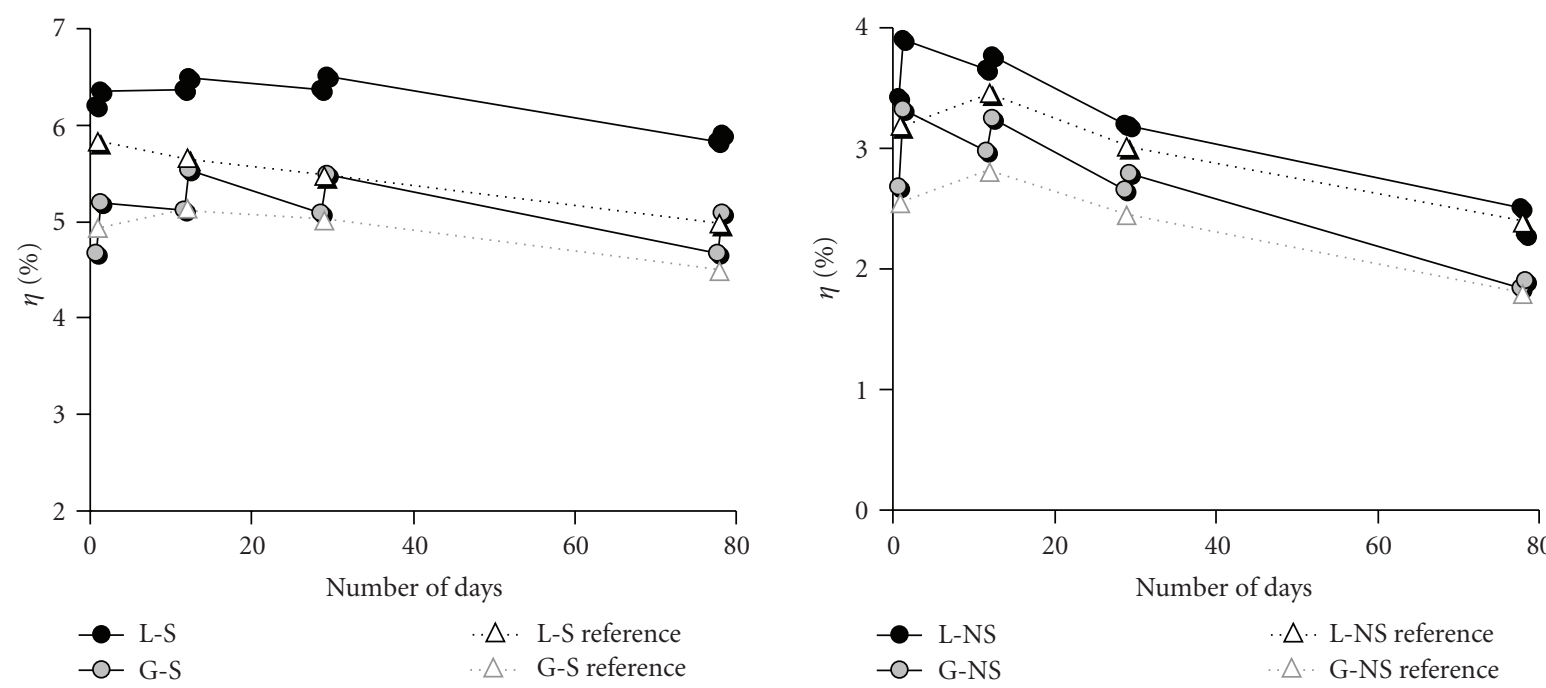

(d)

FIGURE 2: The average IV-parameters as a function of time, before and after every temperature treatment (pairs of two consecutive markers) versus reference cell values. (a) Open circuit voltage $V_{\mathrm{oc}}$, (b) short circuit current density $I_{\mathrm{sc}}$, (c) fill factor FF, and (d) power conversion efficiency $\eta$. Standard deviations are not marked in the figures but their values fell on the range $0-0.01 \mathrm{~V}$ for the $V_{\mathrm{oc}}, 0.4-1 \mathrm{~mA} / \mathrm{cm}^{2}$ for the $I_{\mathrm{sc}}, 1 \%-4 \%$ for the FF, and $0.1 \%-0.5 \%$ for the $\eta$ (the largest values typical to the most aged nonsintered cells). Small initial standard deviations indicated even cell quality which is why the final number of temperature-treated cells could be limited to three and that of the reference cells to two.

examples of the sintered and non-sintered cells' Nyquist plots, respectively.

For the non-sintered cells, photo- and counter electrode impedance arcs overlapped in the highest temperature $\left(70^{\circ} \mathrm{C}\right)$ so widely that in the most cases the exact values for $R_{\mathrm{pe}}$ and $R_{\mathrm{ct}}$ could not be reliably extracted from the data. For the aged (non-sintered) cells this overlapping was often still present when the temperature was lowered from $70^{\circ} \mathrm{C}$ to $40^{\circ} \mathrm{C}$ during the downward sweep of the temperature ramp. In these cases, only the total resistance of the cell and the shape of the photoelectrode impedance arc were monitored more closely.

The series resistances of the cells $\left(R_{s}\right)$, caused mostly by the sheet resistance of the substrate glass, were very similar between all cell types. Their values fell mostly on the range $10-15 \Omega$, and no large changes could be observed as a function of time or temperature.

Supplementary Table 4 lists for the sintered cells for which proper fits could be obtained at all temperatures and on all measurement days the average values of the photoelectrode recombination resistance $R_{\text {rec }}$, the charge transfer resistance on the counter electrode $R_{\mathrm{ct}}$, and the photo- and counter electrode capacitances $C_{\mathrm{pe}}$ and $C_{\mathrm{ce}}$, respectively. The electron lifetimes $\tau_{e}$ in the $\mathrm{TiO}_{2}$ film are calculated with the equation

$$
\tau_{e}=\left(R_{\mathrm{rec}} \cdot B_{0}\right)^{1 / \beta},
$$

where the prefactor $B_{0}$ and the exponent $\beta$ describe the impedance of the constant phase element $\mathrm{CPE}_{\mathrm{pe}}(\omega$ is the angular frequency) [41]:

$$
Z_{\mathrm{CPE}_{\mathrm{pe}}}=\frac{1}{B_{0}}(i \cdot \omega)^{-\beta}
$$

and were obtained from the equivalent circuit fits. Since $\tau_{e}$ can also be interpreted as the time constant of the $R C$-circuit describing the photoelectrode, that is,

$$
\tau_{e}=R_{\mathrm{rec}} \cdot C_{\mathrm{pe}},
$$

combining (1) and (3) enables calculation of the photoelectrode capacitance (equation for the counter electrode capacitance is analogous):

$$
C_{\mathrm{pe}}=\frac{\left(R_{\mathrm{rec}} \cdot B_{0}\right)^{1 / \beta}}{R_{\mathrm{rec}}} .
$$

If both $R_{\mathrm{rec}}$ and $R_{\mathrm{tr}}$ can be obtained from the impedance data, their values can be used to determine the diffusion length $L_{e}$ of the electrons in the $\mathrm{TiO}_{2}$ film [35].

$$
L_{e}=\sqrt{\frac{R_{\mathrm{rec}}}{R_{\mathrm{tr}}}} \cdot d,
$$

where $d$ is the film thickness.

Some difference in the magnitudes of the photoelectrode capacitance values can be noticed between liquid and gel electrolyte cells, the latter having slightly lower $C_{\mathrm{pe}}$. This can be explained with the less efficient penetration of the gel into the pores of the $\mathrm{TiO}_{2}$ layer. If the gel is not properly in touch with the $\mathrm{TiO}_{2}$ particles, the formation of the electrically charged double layer on the $\mathrm{TiO}_{2}$ surface is impossible on those areas. 


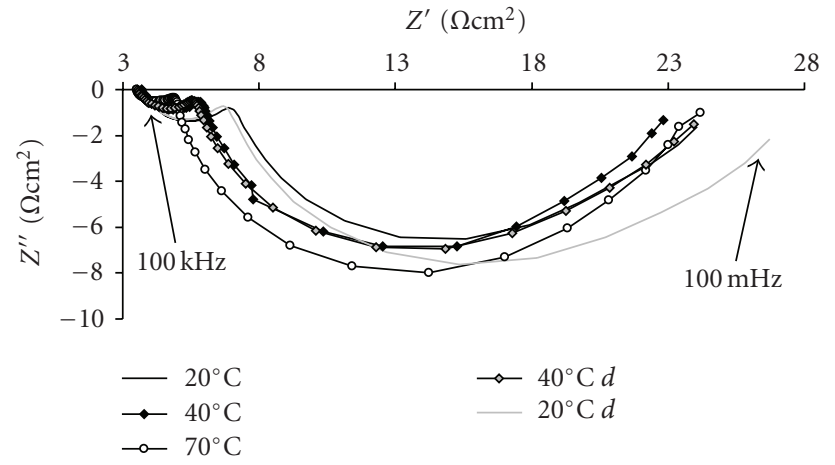

(a)

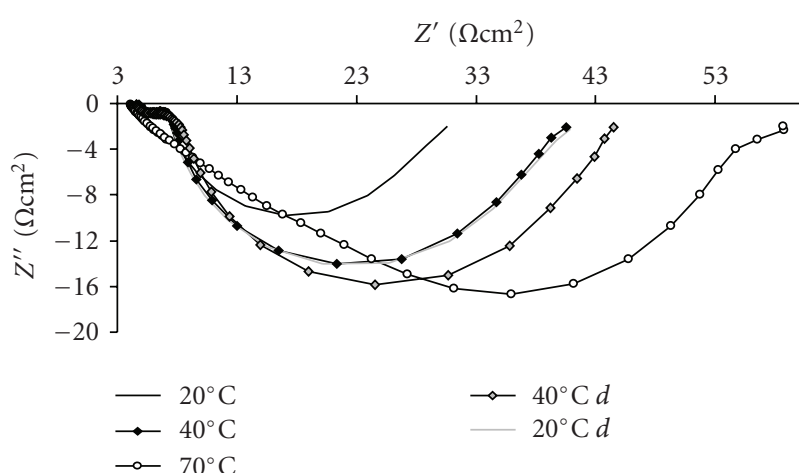

(b)

Figure 3: Typical Nyquist plots for the sintered cells at different temperatures: cell type L-S, measurement day 1 (a) and 78 (b). Letter " $d$ " after the temperature value indicates the downward sweep of the temperature cycle. $Z^{\prime}$ : real impedance; $Z^{\prime \prime}$ : imaginary impedance.

With the first set of EIS measurements, it is important to notice that the temperature behavior of many impedance parameters reflects the temperature-induced changes in the open circuit voltage (i.e., smaller $V_{\text {oc }}$ at higher temperatures). Thus, the observed changes in those parameters are not directly caused by varying temperature but by varying $V_{\text {oc }}$. While evolution of the parameters and changes in their sensitivity to temperature variations as a function of time can be seen from these measurements, detailed analysis of the parameters' temperature dependence is based on the second set of EIS data.

EIS parameters obtained from the second set of measurements were also plotted as a function of the cell current density $i$. Since the same current flows through all cell components, the current density dependence of the differential resistance of the cell component $x, R_{x}$, can be used to calculate the voltage over that component, $V_{x}$, according to $[36,37]$

$$
V_{x}=\int_{i_{0}}^{i} R_{x}(i) d i+V_{0, x} .
$$

The known reference point, that is, the lower limit of the integral, $i_{0}$, and the corresponding voltage, $V_{0, x}$ (the integration constant), can be chosen arbitrarily but here the reference point is open circuit, that is, $V_{0, x}=V_{\mathrm{oc}}$ and $i_{0}=0$. In this way (6) could be used to determine the photoelectrode voltage $V_{\mathrm{pe}}$. Plotting the photoelectrode parameters $R_{\mathrm{rec}}, R_{\mathrm{tr}}, C_{\mathrm{pe}}, \tau_{e}$, and $L_{e}$ as a function of $V_{\mathrm{pe}}$ enabled their analysis independently of the voltage losses in the other cell components.

\subsubsection{Photoelectrode Impedance}

A. Photoelectrode Resistance. The main result of the first set of impedance measurements was the $R_{\mathrm{pe}}$ 's steady increase with time and temperature, though the latter effect is caused by the temperature-induced decrease in the $V_{\mathrm{oc}}$, not directly by temperature itself (temperature-induced decrease in the $V_{\text {oc }}$ of dye solar cells is a well-known effect and it has been reported several times before $[15,16,18,38])$. Figure 5 presents the behavior of $V_{\text {oc }}$ versus $T$ (first set of EIS), and Figure 6 the evolution of $R_{\mathrm{pe}}$ with time and temperature and with time and $V_{\mathrm{oc}}$. Due to a similar, characteristic behavior of the impedance parameters between the cell types, cell type $\mathrm{L}-\mathrm{S}$ is used as the example in all figures to follow (presented values are averages of all samples measured).

It can be seen from Figure 6 that the rise of the $R_{\mathrm{pe}}$ with temperature becomes steeper with time. Judged from the shapes of the photoelectrode impedance arcs, exemplified in Figures 3 and 4, the aged cells' increased sensitivity to the temperature rise was mostly caused by increased transport resistance, which contributed more to the overall resistance the more the cells aged and/or the higher the temperature was. Figures 3 and 4 clearly show the difference between sintered and non-sintered cells: for the former, Gerischershaped photoelectrode impedance, indicating the condition $L_{e}<d$ (large transport resistance, high recombination rate) [24], could not be seen until the last measurements on day 78 at the highest temperature $\left(70^{\circ} \mathrm{C}\right)$. Short, straight line with a slope of $45^{\circ}$ between the photo- and counter electrode impedance arcs, characteristic of the transport resistance, can also be seen in the aged cell's $40^{\circ} \mathrm{C}$ impedance spectra in Figure 3. For the non-sintered cells, the Gerischershape was present already in the first measurements on day 1 , changing in the last highest temperature measurements to a large semicircle. In this case it must be noted that the increase of $R_{\mathrm{pe}}$ in Figure 4 could also originate from increasing $R_{\text {rec }}$ because due to the Gerischer shape of the impedance arc, the resistance components could not be determined separately. However, the data in Figure 3 support the opposite conclusion because the increase of the $R_{\text {tr }}$ can clearly be seen in it (larger $R_{\text {rec }}$ semicircle at elevated temperatures is due to the lower $V_{\text {oc }}$ ). As the cells in Figures 3 and 4 were prepared with the exact same methods and materials, the only difference being that in the former the photoelectrodes were sintered, it is a reasonable assumption that the time and temperature behavior of both cell types is similar. For non-sintered cells, the increase of $R_{\text {tr }}$ is likely to happen even faster, taken that the interparticle contacts and thus the conductivity in a non-sintered $\mathrm{TiO}_{2}$ film are poorer than those in a sintered one, even in the fresh cells. 


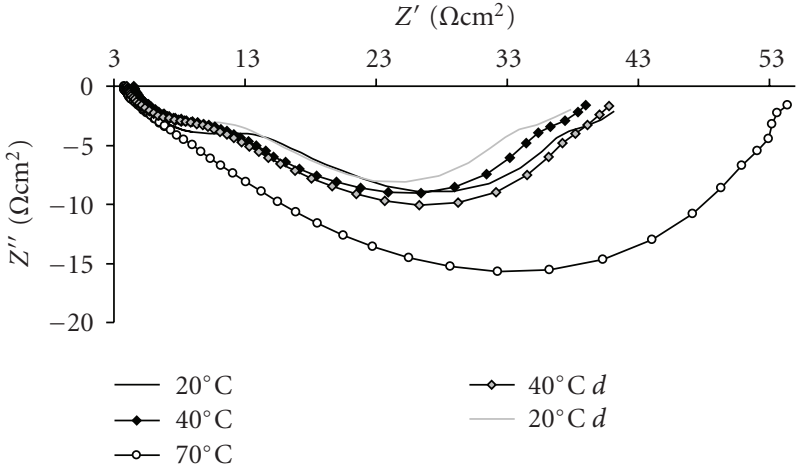

(a)

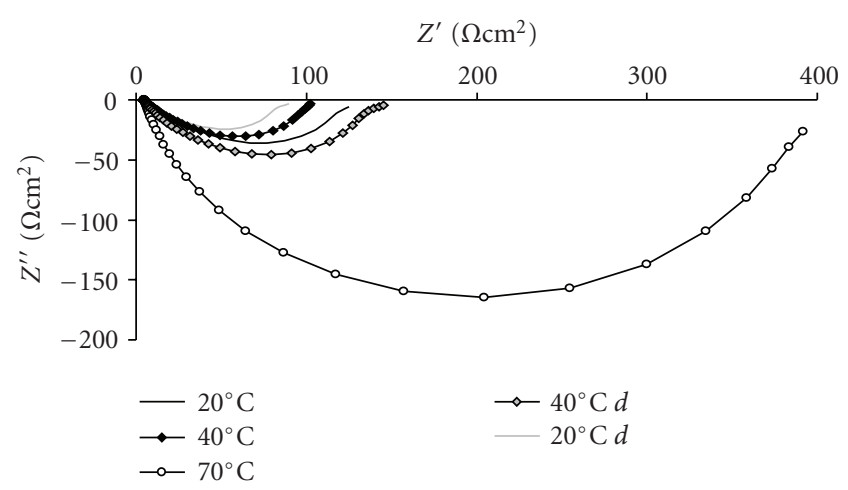

(b)

FIGURE 4: Typical Nyquist plots for the nonsintered cells at different temperatures: cell type L-NS, measurement day 1 (a) and 76 (b). Letter " $d$ " after the temperature value indicates the downward sweep of the temperature cycle. $Z^{\prime}$ : real impedance; $Z$ " : imaginary impedance.

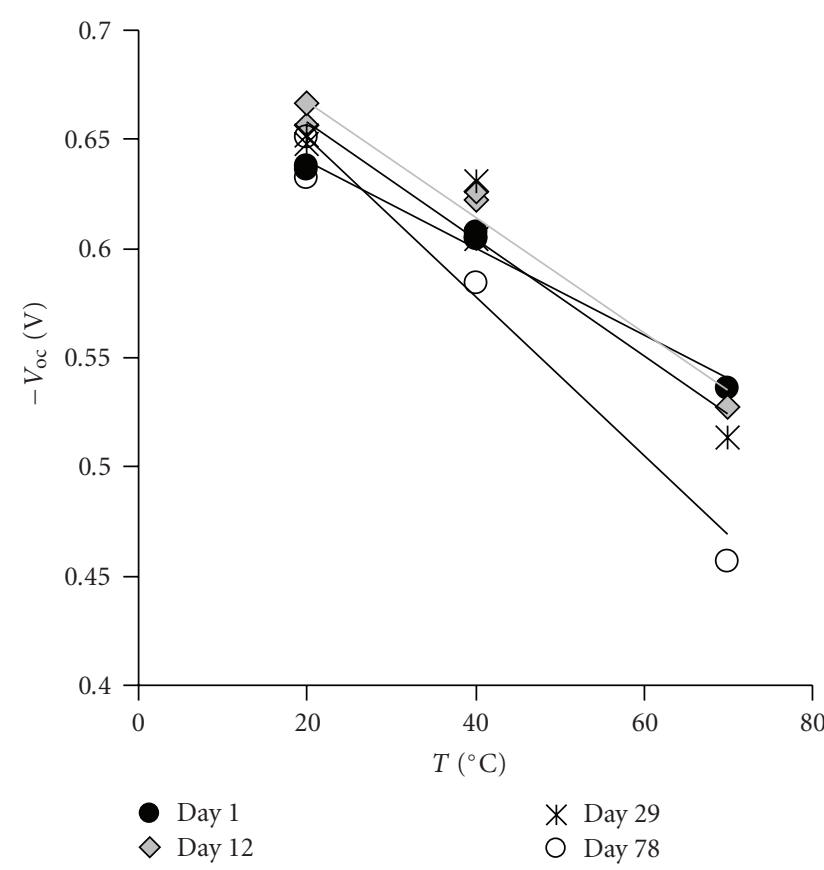

FIGURE 5: Temperature dependence of the open circuit voltage: first set of EIS measurements.

The large semicircle in the aged non-sintered cells' hightemperature spectra, indicating exceptionally poor conductivity in the $\mathrm{TiO}_{2}$ film, is typical for low $V_{\mathrm{oc}}$ (at low open circuit voltages, the electron concentration in the $\mathrm{TiO}_{2}$ film is smaller, hindering efficient charge transport and resulting in higher $R_{\mathrm{tr}}$ ). This radical drop in the photoelectrode's performance was reversible, however, indicating no permanent damage to the film by high temperature. This effect implies that non-sintered $\mathrm{TiO}_{2}$ films are less suitable for high-temperature operating conditions than sintered films.

The second set of impedance measurements provided more information about the direct temperature behavior of the $R_{\text {pe }}$ components. Unlike in the first set, where either the characteristic of the $R_{\mathrm{tr}}$ was overlapped by the counter electrode impedance or the photoelectrode arc took the shape of Gerischer impedance, rendering extraction of $R_{\mathrm{tr}}$ impossible, here the $R_{\text {pe }}$ components were distinguishable enough to be obtained separately from the equivalent circuit fits. The current density dependence of $R_{\text {rec }}, R_{\text {rec }}(i)$, along with the bias voltage dependence of $i, i(V)$, both illustrated in Figure 7, could now be used to calculate the photoelectrode voltage $V_{\text {pe }}$, according to (6). Exponential functions of the type

$$
R_{\mathrm{rec}}(i)=A \cdot e^{B \cdot i}
$$

were fitted to the $R_{\text {rec }}$ versus $i$ data at different temperatures, and second-order polynomials, from which the $V_{\text {oc }}$ values needed in (6) could be obtained, to the $i$ versus $V$ data. Both sets of fits are included in Figure 7. After inserting (7) into (6) and integrating, $V_{\text {pe }}$ could be obtained from the expression

$$
V_{\mathrm{pe}}=\frac{A}{B}\left(e^{B \cdot i}-1\right)+V_{\mathrm{oc}}
$$

Figure 8 presents the temperature dependence of $R_{\text {rec }}$ and $R_{\mathrm{tr}}$ at different photoelectrode voltages. In the rest of this paper, all other photoelectrode parameters obtained from the data of the second set of EIS measurements are similarly presented as a function of $V_{\text {pe }}$.

The temperature behavior of the $R_{\text {pe }}$ components presented in Figure 8 is partially in agreement with the regeneration of the short circuit current after the temperature ramping, which was observed in several of our previous measurements. When the temperature is increased, both $R_{\mathrm{tr}}$ and $R_{\text {rec }}$ decrease, but when it is lowered again, the effect is overcompensated by both resistances reaching higher values than those before the ramp. Higher $R_{\text {rec }}$ inhibits recombination and through (1) and (5), respectively, can contribute to a longer electron lifetime and diffusion length. Longer diffusion length, in turn, increases the probability that the electrons reach the current collector before recombination, thus resulting in higher short circuit photocurrent.

According to the (simplified) equation

$$
v_{\mathrm{rec}}=k_{\mathrm{rec}}(n) \cdot n \text {, }
$$




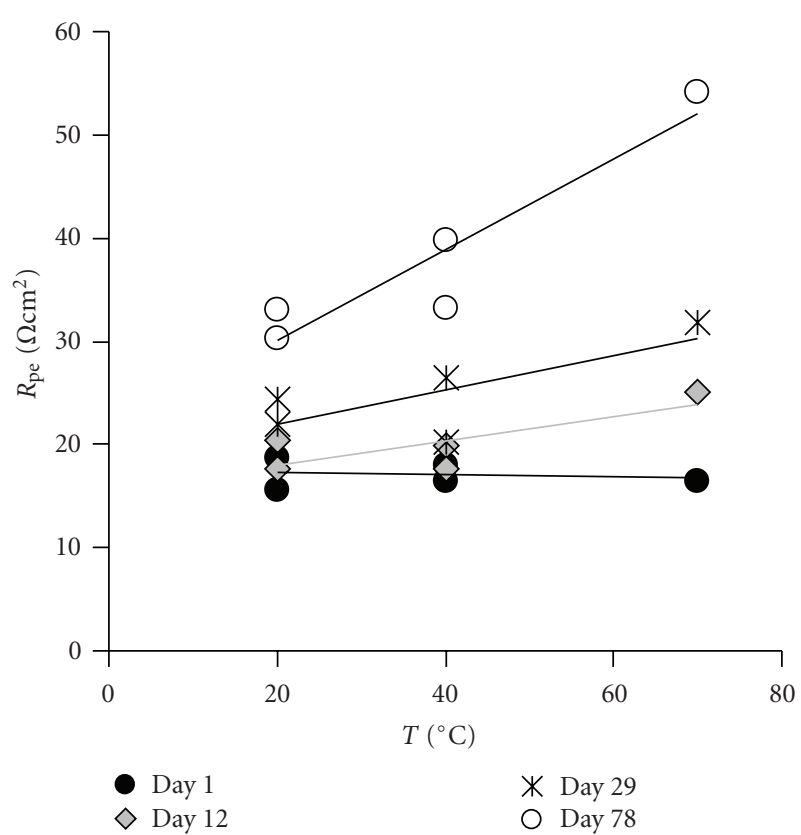

(a)

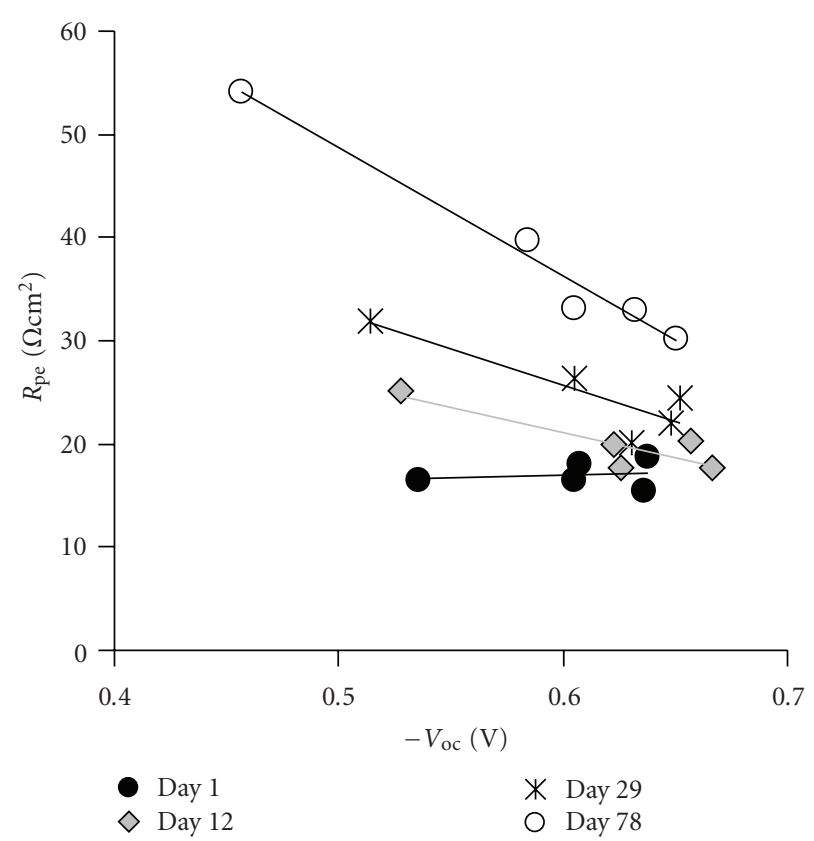

(b)

FIGURE 6: Photoelectrode (total) resistance as a function of temperature (a) and open circuit voltage (b) on different measurement days; first set of EIS measurements.

where $v_{\text {rec }}$ is the recombination rate, $k_{\text {rec }}$ the recombination rate constant, and $n$ the electron concentration in the $\mathrm{TiO}_{2}$ film (including, here, both the conduction band and band gap trap state electrons), the decrease in $R_{\text {rec }}$ at elevated temperatures and higher voltages can be explained with the temperature-induced increase in $k_{\text {rec }}$ and larger electron concentration in the $\mathrm{TiO}_{2}$ film, respectively $[15,18]$. Faster recombination at elevated temperatures is responsible also for the smaller $V_{\mathrm{oc}}$. Similarly, the decrease of $R_{\mathrm{tr}}$ at higher temperatures and voltages can be deduced to originate from increased electron concentration. Higher temperature lifts electrons from the band gap trap states to the conduction band, thus increasing the conductivity of the $\mathrm{TiO}_{2}$ film $[15,18]$.

The temperature behavior of $R_{\mathrm{rec}}$ and $R_{\mathrm{tr}}$ is in agreement with literature also $[35,36]$. Both resistances have exponential voltage dependence:

$$
\begin{aligned}
R_{\mathrm{rec}} & =R_{0} \exp \left[\frac{-\beta}{k_{B} T}\left(E_{\mathrm{Fn}}-E_{\mathrm{redox}}\right)\right], \\
R_{\mathrm{tr}} & =R_{t 0} \exp \left[\frac{-e}{k_{B} T}\left(V+\frac{E_{\mathrm{redox}}-E_{\mathrm{cb}}}{e}\right)\right],
\end{aligned}
$$

where $R_{0}$ and $R_{t 0}$ are constants, $\beta$ the transfer coefficient for Butler-Volmer type charge transfer reaction, $e$ the elementary charge, $T$ the absolute temperature, $k_{B}$ the Boltzmann constant, $E_{\mathrm{Fn}}$ the position of the Fermi level of the electrons, $E_{\mathrm{cb}}$ the energy of the conduction band, and $E_{\text {redox }}$ the redox Fermi level of the electrolyte $\left(E_{\mathrm{Fn}}-E_{\text {redox }}=e V_{\mathrm{pe}}\right)$. The slope $d\left(\log R_{\text {rec/tr }}\right) / d V$ changes with temperature, which can be seen in $R_{\text {tr }}$ in Figure 8 (with $R_{\text {rec }}$ the change in the slope is not so evident, but this can be due to a rather small amount of measurements points and a narrow voltage range).

When $\ln \left(R_{\mathrm{tr}}\right)$ was plotted as a function of $1 / T$ at fixed voltage, however, deviation from linear dependence could be observed between $40^{\circ} \mathrm{C}$ and $70^{\circ} \mathrm{C}$ (data not shown). According to (11), this indicates temperature dependence in either $R_{t 0}$ or $\left(E_{\text {redox }}-E_{\mathrm{cb}}\right)$.

B. Photoelectrode Capacitance. Photoelectrode capacitance is plotted in Figure 9 as a function of time, temperature, and $V_{\text {oc }}$ (first set of EIS). $C_{\mathrm{pe}}$ decreased with time and temperature, the latter effect reflecting again the decrease of the $V_{\mathrm{oc}}$ as a function of $T$. On the voltage range used in this study, $C_{\mathrm{pe}}$ consists of the capacitance on the $\mathrm{TiO}_{2}$-electrolyte interface, $C_{\mathrm{dl}}$, and the chemical capacitance of the $\mathrm{TiO}_{2}$ film, $C_{\mu}$, which exhibits exponential voltage dependence $[35,36]$ :

$$
C_{\mu}=\frac{e^{2}}{k_{B} T} \exp \left[\frac{\alpha}{k_{B} T}\left(V+\frac{E_{\mathrm{redox}}-E_{\mathrm{cb}}}{e}\right)\right] .
$$

$\alpha=T / T_{0}$, where $T_{0}$ is a parameter (in temperature units) which determines the depth of the band gap states' distribution versus the lower edge of the conduction band. Due to the narrow voltage range in our measurements, however, the exponential shape of the curve cannot clearly be seen and the dependence appears to be linear.

Figure 10 presents the direct temperature dependence of the $C_{\mathrm{pe}}$ (second set of EIS measurements). An increase in $C_{\mathrm{pe}}$ at elevated temperatures can be seen, overcompensated, at the higher photoelectrode voltages during the downward temperature sweep, by its decrease to values lower than those before the temperature ramping (i.e., opposite effect to that 


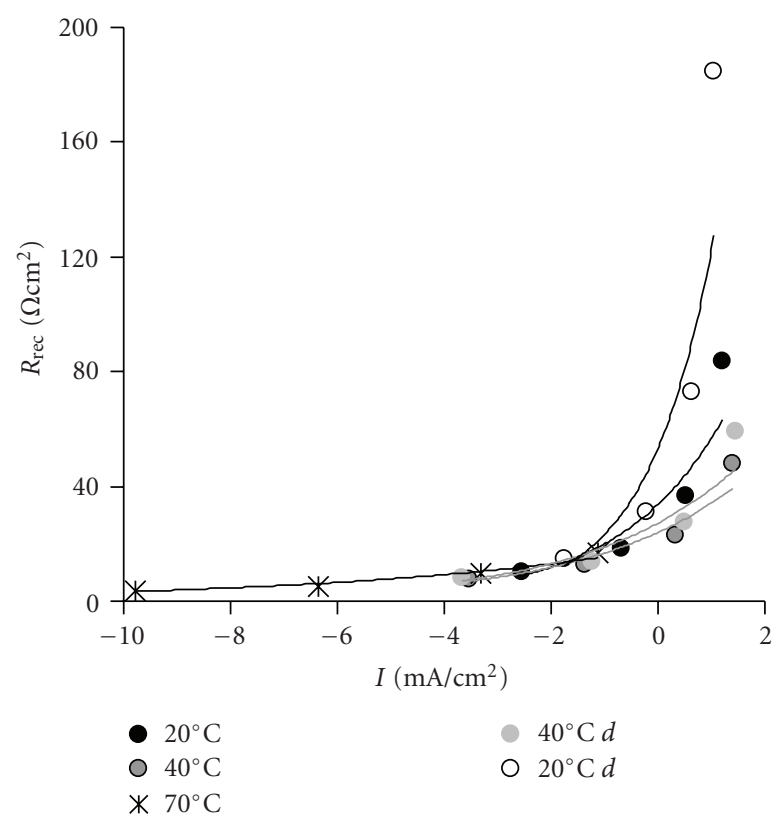

(a)

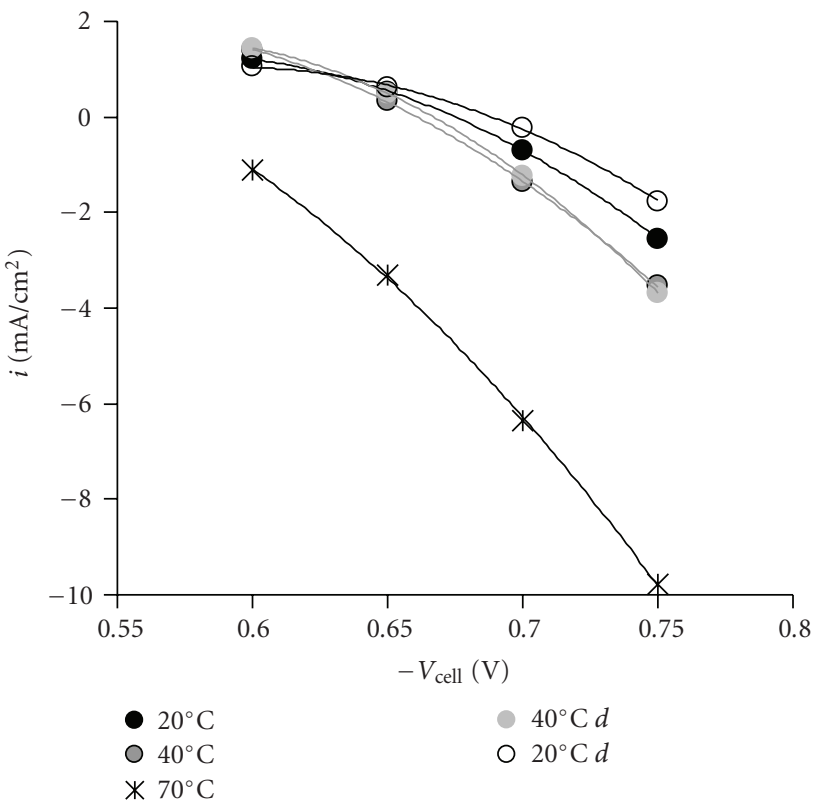

(b)

Figure 7: Recombination resistance as a function of current density (a) and current density as a function of cell voltage (b), at different temperatures; second set of EIS measurements. Letter " $d$ " after the temperature value indicates the downward sweep of the temperature cycle.

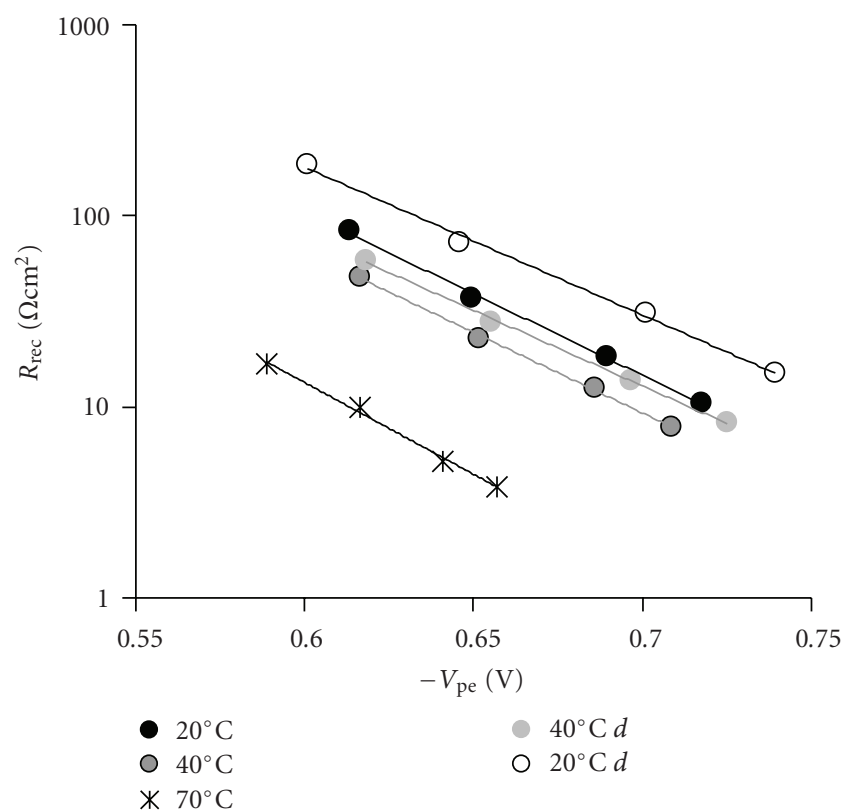

(a)
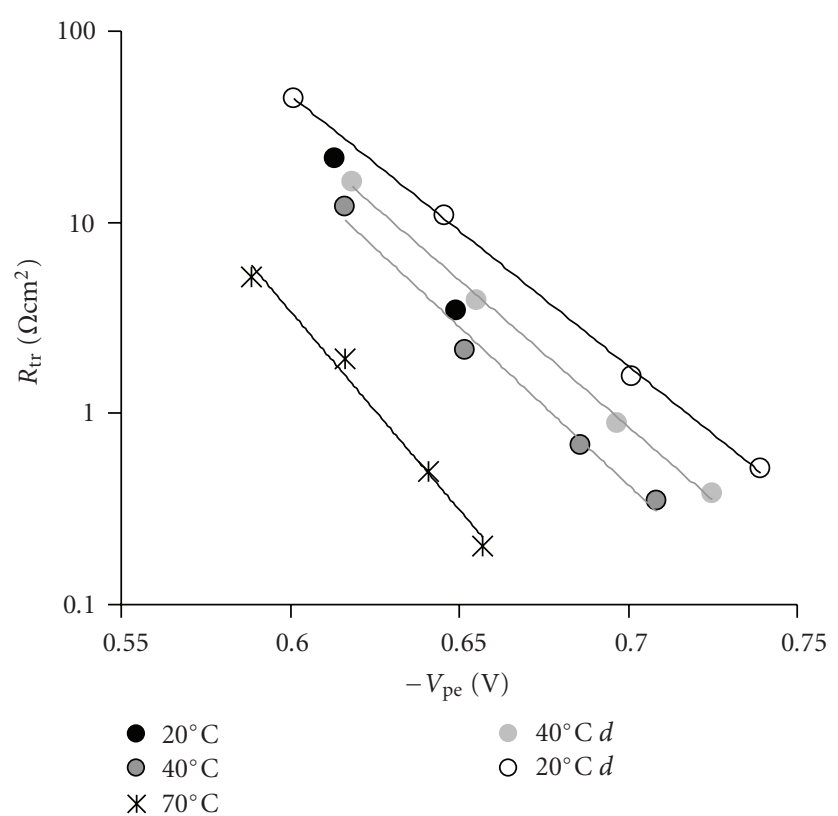

(b)

FIGURE 8: Recombination resistance (a) and transport resistance (b) as a function of photoelectrode voltage, at different temperatures; second set of EIS measurements. Letter " $d$ " after the temperature value indicates the downward sweep of the temperature cycle.

of the $R_{\mathrm{pe}}$ components). This seems to be in disagreement with [35], in which $C_{\mathrm{pe}}$ remained practically independent of temperature between $0^{\circ} \mathrm{C}$ and $60^{\circ} \mathrm{C}$, and also with (12), according to which an increase in $T$ should result in decrease in $C_{\mu}$, unless temperature-induced shifts in $\left(E_{\mathrm{redox}}-E_{\mathrm{cb}}\right)$ happen. The slope $d\left(\log C_{\mathrm{pe}}\right) / d V$ appears independent on temperature, though, and is thus in agreement with the previously observed behavior [35]. Our results are also in agreement with [21], where the $C_{\mathrm{pe}}$ clearly increased with temperature. 


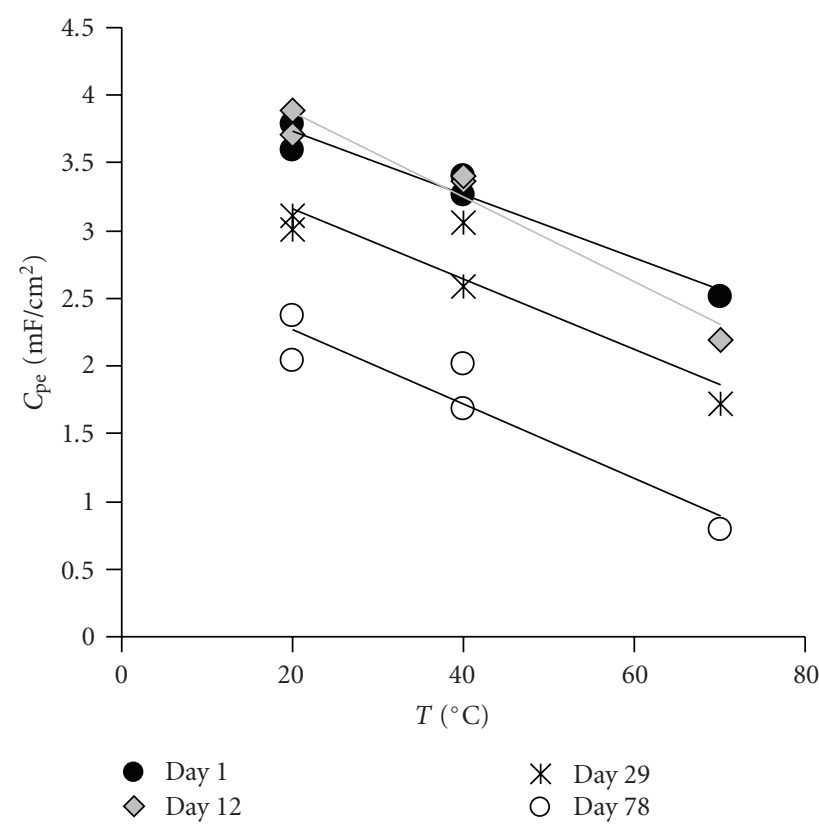

(a)

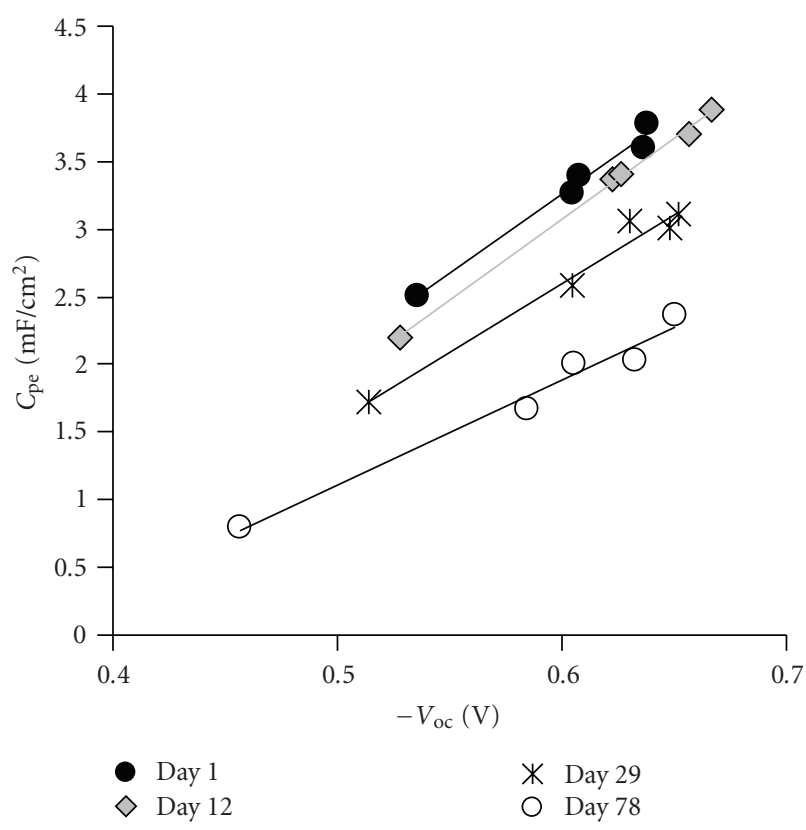

(b)

FIGURE 9: Photoelectrode capacitance as a function of temperature (a) and open circuit voltage (b); first set of EIS measurements.

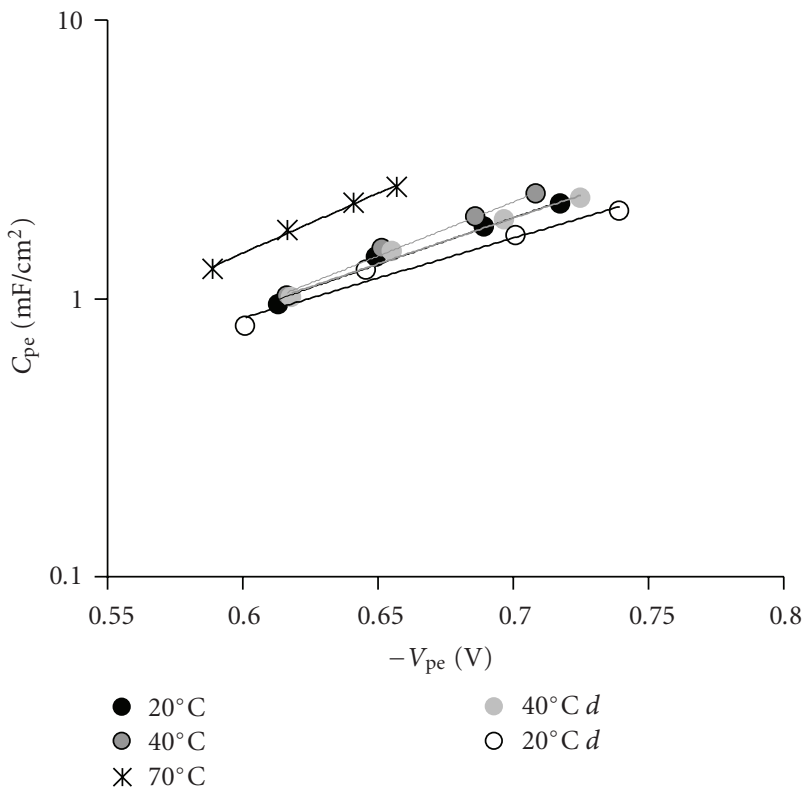

Figure 10: Photoelectrode capacitance as a function of photoelectrode voltage, at different temperatures; second set of EIS measurements. Letter " $d$ " after the temperature value indicates the downward sweep of the temperature cycle.

$C_{\mathrm{pe}}$ was also plotted as a function of $1 / T$, keeping the voltage fixed (data not shown). Analogously to $R_{\mathrm{tr}}$, deviation from linear dependence was observed at high temperatures. This indicates again temperature-induced changes in either $T_{0}$ or $\left(E_{\text {redox }}-E_{\mathrm{cb}}\right)$. Based on the earlier observation, however, that the $C_{\mathrm{pe}}$ 's increase with temperature contradicts the behavior predicted by (12), unless temperature-induced shifts in $\left(E_{\text {redox }}-E_{\mathrm{cb}}\right)$ happen, a reasonable assumption is that the deviation from linearity when $C_{\mathrm{pe}}$ is plotted against $1 / T$ is, indeed, caused by temperature-induced variation in $E_{\mathrm{cb}}$ and/or $E_{\text {redox. }}$. This would be in agreement also with [21].

Direct proof of the origin of the $C_{\mathrm{pe}}$ 's contradictory temperature behavior could not be obtained from our EIS measurements, but temperature is likely to affect the chemical composition of the $\mathrm{TiO}_{2}$ surface, that is, concentrations of the electrolyte additives, dye, and possible impurities on it. Increased adsorption of ions at elevated temperatures could result in larger $C_{\mathrm{pe}}$ values, and correspondingly, their desorption when the temperature is lowered again, to smaller $C_{\mathrm{pe}}$. One reason for the inconsistency of our result and [21] with [35] could also be in lighting conditions-in [21], the measurements were made under illumination, like in our study, whereas in [35], in the dark. Basically, lighting conditions only affect the "direction" from which the electrons are fed into the $\mathrm{TiO}_{2}$ film - under illumination, they come from the dye and in the dark, from the external circuit, their total amount in the film then setting the photoelectrode voltage which, in turn, directly affects the photoelectrode capacitance. The fact that there is temperature dependence in the capacitance when the electrons are fed to the $\mathrm{TiO}_{2}$ from the dye could thus reflect temperature-dependent changes in the dye- $\mathrm{TiO}_{2}$ interface or the chemical structure of the dye.

C. Electron Lifetime and Diffusion Length. According to (1) and (5), the behavior of $\tau_{e}$ and $L_{e}$ reflects the behavior of $R_{\mathrm{rec}}, C_{\mathrm{pe}}$, and $R_{\mathrm{tr}}$. Figures 11 and 12 present $\tau_{e}$ as a function of time, temperature, and $V_{\mathrm{oc}}$, and as a function of photoelectrode voltage at different temperatures, respectively. 


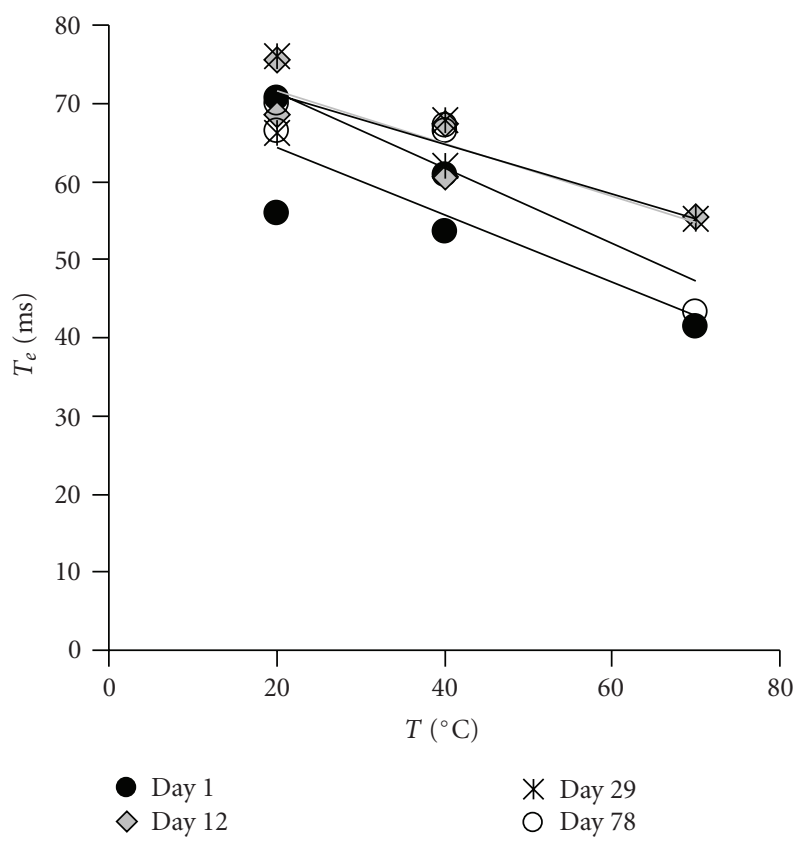

(a)

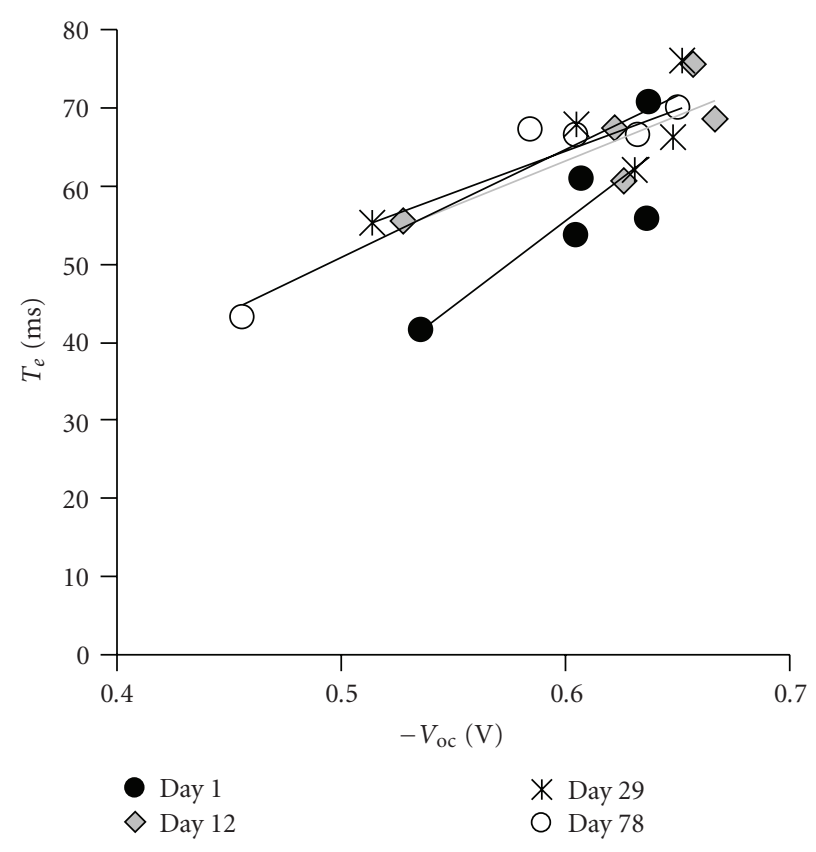

(b)

FIgURE 11: Electron lifetimes in the $\mathrm{TiO}_{2}$ film, as a function of temperature (a) and open circuit voltage (b); first set of EIS measurements.

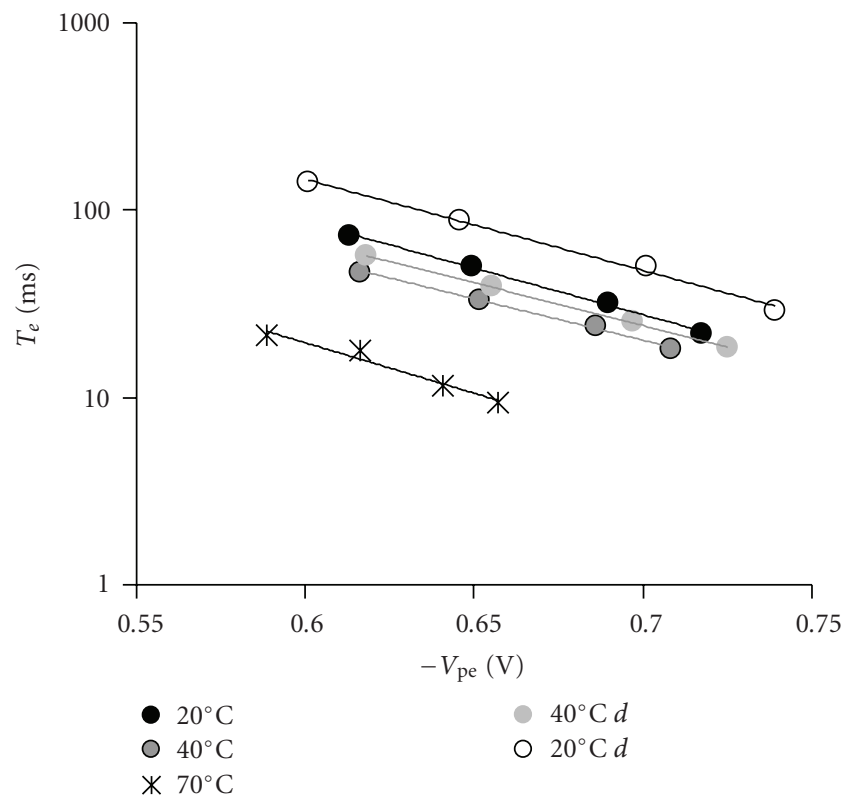

FIGURE 12: Electron lifetimes in the $\mathrm{TiO}_{2}$ film, as a function of photoelectrode voltage, at different temperatures; second set of EIS measurements. Letter " $d$ " after the temperature value indicates the downward sweep of the temperature cycle.

In Figure 13, $L_{e}$ is plotted as a function of photoelectrode voltage, at different temperatures also.

The seeming contradiction between the voltage dependence of $\tau_{e}$ in Figures 11 and 12 can be explained with the different nature of the measurements. In Figure 11, the measured voltage is that generated by the cell at open circuit, the points of higher voltage representing lower temperatures. At lower temperature, slower recombination results in longer electron lifetimes and the cell can sustain higher (open circuit) voltage. In Figure 12, the voltage is set externally, that is, larger electron concentration in the film results in faster recombination, thus lowering the $\tau_{e}$ as well.

Despite that $C_{\mathrm{pe}}$ increases as a function of temperature, this effect was not large enough to affect the electron lifetimes, which were shorter at elevated temperatures following directly the trend in $R_{\text {rec }}$, even to the overcompensating effect during the downward sweep of the ramp. However, the $\tau_{e}$ in Supplementary Table 4 are not, in general, and within the limits of the measurement accuracy, higher after the temperature rampings than before those, especially in the case of the aged cells. The major increase seems to happen between the consecutive measurement days (i.e., the $\tau_{e}$ in the end of the previous ramp are much lower than in the beginning of the next). This indicates that the overall efficiency regeneration is not solely caused by the beneficial effects of the temperature rampings on the photoelectrode characteristics but also caused by other factors such as improvement in the counter electrode function. In any case, even with the aged cells, the rampings, and aging in general, did not result in noticeable decrease in $\tau_{e}$ as can be seen from Figure 11.

The parallel changes in $R_{\mathrm{rec}}$ and $R_{\mathrm{tr}}$ with temperature as discussed in Section 3.2.2(A) are directly reflected in the temperature behavior of $L_{e}$ (Figure 13). In the limits of measurement accuracy, electron diffusion length shows very small and irregular variation with temperature on the observed voltage range. This is, interestingly, also in disagreement with [35] in which clear, regular temperature 


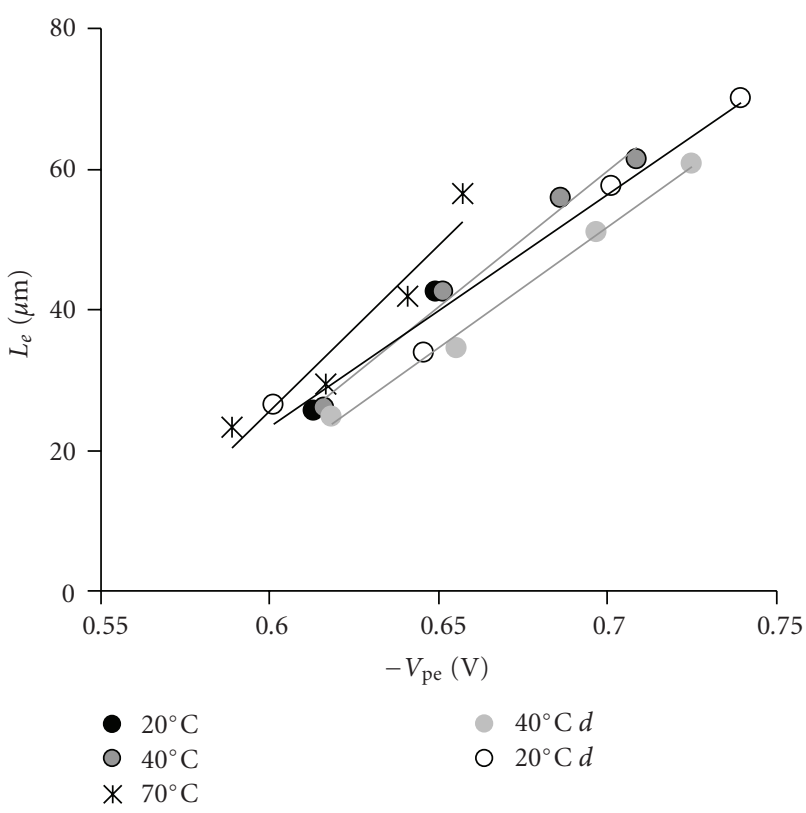

Figure 13: Electron diffusion lengths in the $\mathrm{TiO}_{2}$ film, as a function of photoelectrode voltage, at different temperatures; second set of EIS measurements. Letter " $d$ " after the temperature value indicates the downward sweep of the temperature cycle.

dependence was observed. As a function of $V_{\mathrm{pe}} L_{e}$ increases linearly, indicating relatively larger drop in $R_{\text {tr }}$ in comparison to $R_{\text {rec }}$ with increasing voltage.

3.2.3. Counter Electrode Impedance. Since the same type of counter electrode (platinized glasses prepared in the same batch) was employed in all cells, the time and temperature behavior of the charge transfer resistance on it followed very regular and similar pattern for all cell types, the only noticeable difference being relatively larger $R_{\mathrm{ct}}$ values for the non-sintered cells. Figures 14 and 15 present $R_{\mathrm{ct}}$ as a function of time, temperature, and $V_{\text {oc }}$ (first set if EIS measurements), and as a function of bias voltage at different temperatures (second set of EIS measurements), respectively.

$R_{\mathrm{ct}}$ exhibited the most regular temperature dependence of all the impedance parameters. Linear decrease was observed as a function of temperature, which can be easily understood by the more efficient function of the Pt catalyst at elevated temperatures. During the downward sweep of the temperature ramp, the $R_{\mathrm{ct}}$ values set on slightly lower levels than what they had reached during the upward sweep, both for the fresh and aged cells (Figure 14), which suggests that the gain in the catalytic efficiency caused by the temperature increase had at least temporary permanence. This can partially explain the regenerating effect of the temperature rampings on the overall cell efficiencies and is in agreement with previous results [38].

The voltage dependence of the $R_{\mathrm{ct}}$ seems to be opposite in Figures 14 and 15, but, as in the case of $\tau_{e}$, is caused by different experimental conditions. In Figure 14, the lines connect points measured at different temperatures whereas in Figure 15 they display the voltage dependence at fixed temperature.

Only slight increase in $R_{\mathrm{ct}}$ or none as a function of time could be detected. This indicates stable counter electrode quality in general, that is, no significant detachment of the Pt catalyst or other degradation mechanisms affecting the electrode performance.

Counter electrode capacitance $C_{\mathrm{ce}}$ was also obtained from the equivalent circuit fits. Slight decrease with time could be observed for the $C_{\mathrm{ce}}$ but no clear, regular temperature dependence could be seen (data not shown).

\section{Summary and Conclusions}

We have used electrochemical impedance spectroscopy to investigate the origins of time- and temperature-induced changes in the dye solar cell performance. The cells were subjected to temperature variations in repeated and regular to-and-fro ramps between $20^{\circ} \mathrm{C}$ and $70^{\circ} \mathrm{C}$ during their aging, and their EIS spectra were recorded as a function of temperature along every ramp after which extensive analysis of the time and temperature behavior of the impedance parameters was performed. IV-curves of the cells were also obtained in a solar simulator before and after the temperature rampings to monitor the evolution of the cell performance parameters with time.

Linearly decreasing charge transfer resistance on the counter electrode as a function of temperature was verified and it can be associated with the temperature-dependent activity of the Pt catalyst. This effect was reversible, though slight hysteresis was observed, that is, lower $R_{\mathrm{ct}}$ values during the downward sweep of the ramp, compared to those in its upward sweep. It also showed short-term permanence (i.e., the $R_{\mathrm{ct}}$ values stayed on lower level several hours after the ramping), which can partially explain the slower deterioration rate of the temperature-treated cells in comparison to the reference cells aged at constant temperature. No significant increase in the $R_{\mathrm{ct}}$ could be observed as a function of time either, indicating good and stable counter electrode quality in general.

Photoelectrode resistance increased with both time and temperature, the latter effect reflecting the lower $V_{\mathrm{oc}}$ at elevated temperatures. The central trend in the $R_{\mathrm{pe}}$ evolution with time was a gradual increase of the electron transport resistance in the $\mathrm{TiO}_{2}$ film, especially in the case of nonsintered cells and favored by temperature elevation.

The direct temperature behavior of the $R_{\mathrm{pe}}$ components could be obtained from the second set of EIS measurements, where the cell voltage was controlled with external polarization. When the current flowing through the cell was known, the photoelectrode voltage could be obtained and the impedance parameters plotted as its function, which enabled their analysis independently of the voltage losses on the other cell components. Both $R_{\text {rec }}$ and $R_{\text {tr }}$ decreased with temperature, and hysteresis was observed in this case also; that is, both components reached higher than original values during the downward sweep of the temperature ramp. The exact reason for the hysteresis remains open this far, though the 


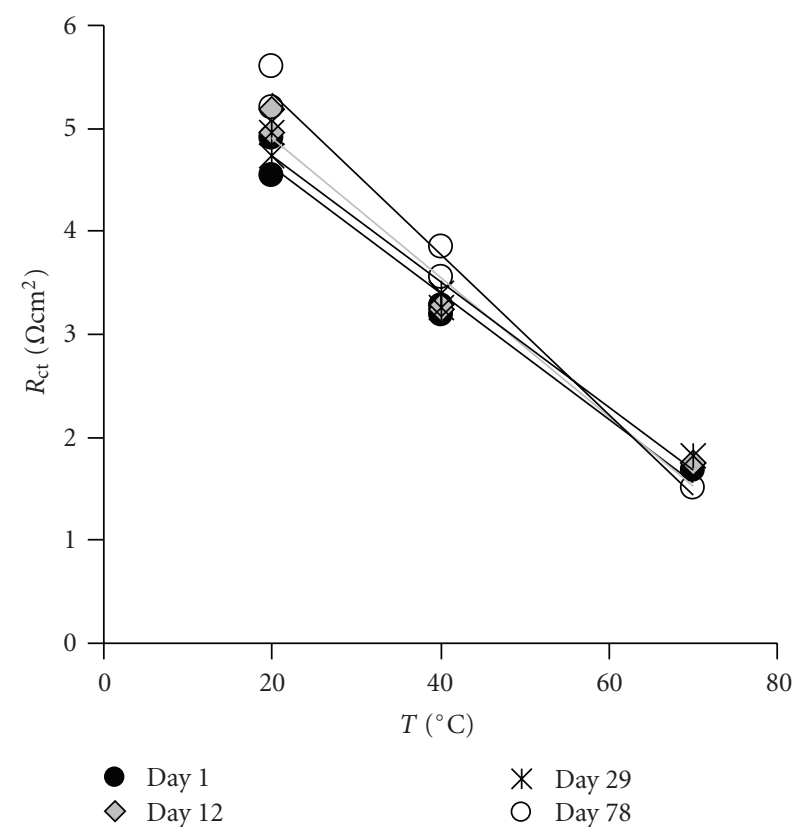

(a)

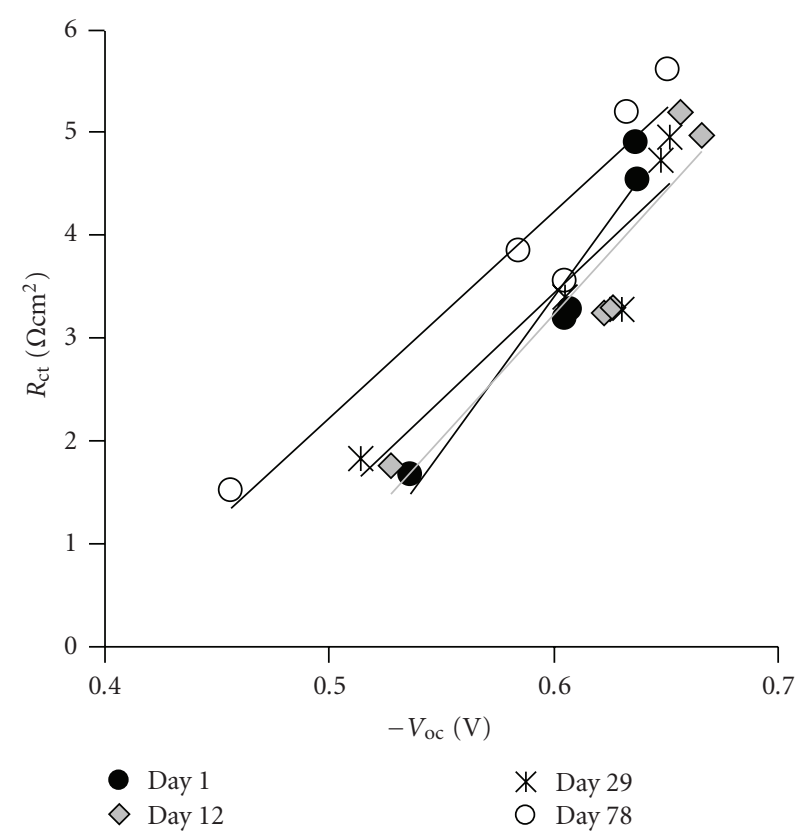

(b)

FIGURE 14: Charge transfer resistance on the counter electrode as a function of temperature (a) and open circuit voltage (b). First set of EIS measurements.

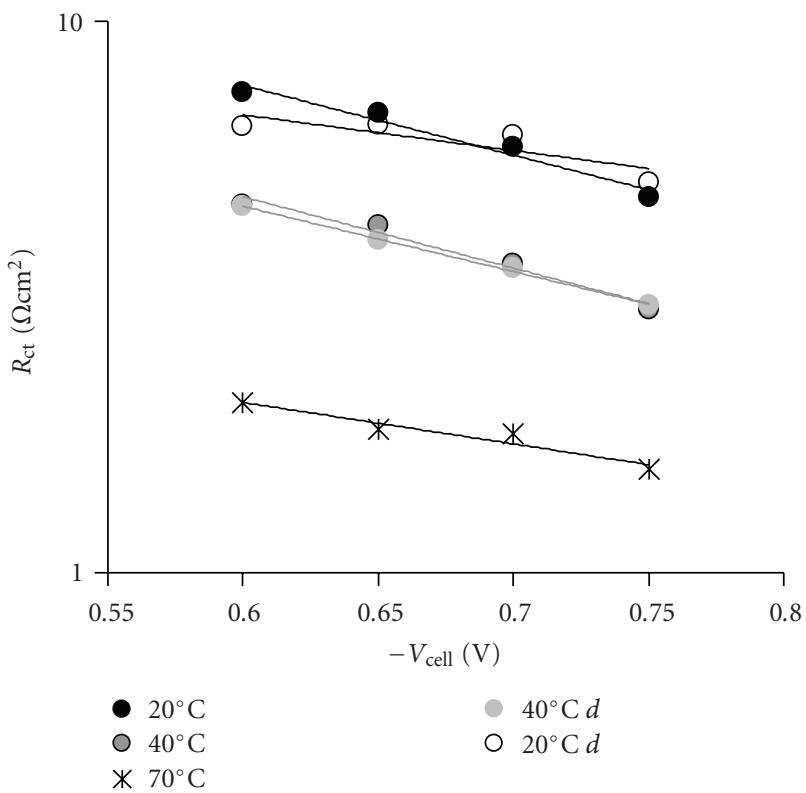

FIGURE 15: Charge transfer resistance on the counter electrode as a function of cell voltage; second set of EIS measurements. Letter " $d$ " after the temperature value indicates the downward sweep of the temperature cycle.

behavior of $R_{\mathrm{rec}}$ could, through longer $L_{e}(5)$, correlate to the $i_{\text {sc }}$ regeneration observed after several temperature rampings. Higher diffusion length results in more electrons reaching the current collector before recombination-however, the problem with this kind of analysis is that the voltage drop inside the $\mathrm{TiO}_{2}$ layer (which affects the $L_{e}$ ) is unknown at short circuit. Temperature-induced variation in $L_{e}$ was also quite small and irregular in this study, contradicting the results in [35].

Photoelectrode capacitance decreased with time but increased as a function of temperature. The behavior of $C_{\mathrm{pe}}$ exhibited slight hysteresis too, resulting in lower capacitance values in the end of the temperature ramp, compared to those before it. The behavior of $C_{\mathrm{pe}}$, as observed here, is also somewhat contradictory compared to earlier studiesin [35], $C_{\mathrm{pe}}$ was found to be independent on temperature, whereas in [21], similar behavior to this research was seen. The behavior of $C_{p e}$ as a function of $1 / T$ at fixed voltage indicated temperature-induced shifts in the conduction band energy $E_{\mathrm{cb}}$ and/or redox Fermi level $E_{\text {redox }}$, also in agreement with [21].

Electron lifetime in the $\mathrm{TiO}_{2}$ film decreased as a function of temperature, reflecting the behavior of $R_{\text {rec }}$. During aging, no noticeable deterioration could be observed for $\tau_{e}$.

An interesting feature in the IV-curve measurements was the increase in the $V_{\text {oc }}$ in the beginning of the aging period. This was accompanied with slight enhancement in the $\tau_{e}$ as well. The exact reason for this behavior remains unresolved at this point, though slow adjustment of the final equilibrium between the dye, TBP, and other adsorbent species on the $\mathrm{TiO}_{2}$ film surface can be assumed to be partly responsible of it. Otherwise the aging behavior of the cells was normal, that is, after the initial rise slow degradation in all parameters; especially in the non-sintered cells. In most cases the short circuit currents were regenerated in the temperature treatments, however, especially for the 
gel electrolyte filled cells, which slowed down the overall performance degradation.

In general, the cells in this study exhibited good longterm stability. With the best cells only slight decrease in efficiency or not at all was detected in the last measurements on days 76-78, indicating that instead of being detrimental to the cell operation, repeatedly and regularly varying temperature could even improve the long-term stability of the conventional, iodine electrolyte-filled DSC, taken that the cell temperature does not exceed ca. $60^{\circ} \mathrm{C}$ for extended periods of time.

EIS proved to be an efficient tool to extract detailed information about the charge transfer/accumulation processes in the cells, and how they relate to the behavior of the IV-curves as a function of time and temperature. The beneficial effect of the temperature rampings on the cell long-term performance was verified, though other types of measurements, for example, spectroscopic techniques, could still be useful in clarifying the physicochemical processes on the $\mathrm{TiO}_{2}$-electrolyte interface.

\section{Acknowledgment}

Financial support from the National Technology Agency of Finland (Tekes) is gratefully acknowledged.

\section{References}

[1] B. O’Regan and M. Grätzel, "A low-cost, high-efficiency solar cell based on dye-sensitized colloidal $\mathrm{TiO}_{2}$ films," Nature, vol. 353, no. 6346, pp. 737-740, 1991.

[2] M. Grätzel, "The magic world of nanocrystals, from batteries to solar cells," Current Applied Physics, vol. 6, supplement 1, pp. e2-e7, 2006.

[3] M. K. Nazeeruddin, P. Péchy, S. M. Renouard, et al., "Engineering of efficient panchromatic sensitizers for nanocrystalline $\mathrm{TiO}_{2}$-based solar cells," Journal of the American Chemical Society, vol. 123, no. 8, pp. 1613-1624, 2001.

[4] M. K. Nazeeruddin, T. Bessho, L. Cevey, et al., "A high molar extinction coefficient charge transfer sensitizer and its application in dye-sensitized solar cell," Journal of Photochemistry and Photobiology A, vol. 185, no. 2-3, pp. 331-337, 2007.

[5] H. Pettersson and T. Gruszecki, "Long-term stability of low-power dye-sensitised solar cells prepared by industrial methods," Solar Energy Materials and Solar Cells, vol. 70, no. 2, pp. 203-212, 2001.

[6] H. Pettersson, T. Gruszecki, L.-H. Johansson, and P. Johander, "Manufacturing method for monolithic dye-sensitised solar cells permitting long-term stable low-power modules," Solar Energy Materials and Solar Cells, vol. 77, no. 4, pp. 405-413, 2003.

[7] P. M. Sommeling, M. Späth, H. J. P. Smit, N. J. Bakker, and J. M. Kroon, "Long-term stability testing of dye-sensitized solar cells," Journal of Photochemistry and Photobiology A, vol. 164, no. 1-3, pp. 137-144, 2004.

[8] R. Sastrawan, J. Beier, U. Belledin, et al., "New interdigital design for large area dye solar modules using a lead-free glass frit sealing," Progress in Photovoltaics: Research and Applications, vol. 14, no. 8, pp. 697-709, 2006.
[9] A. Hinsch, J. M. Kroon, R. Kern, et al., "Long-term stability of dye-sensitised solar cells," Progress in Photovoltaics: Research and Applications, vol. 9, no. 6, pp. 425-438, 2001.

[10] B. Macht, M. Turrión, A. Barkschat, P. Salvador, K. Ellmer, and H. Tributsch, "Patterns of efficiency and degradation in dye sensitization solar cells measured with imaging techniques," Solar Energy Materials and Solar Cells, vol. 73, no. 2, pp. 163173, 2002.

[11] T. Toyoda, T. Sano, J. Nakajima, et al., "Outdoor performance of large scale DSC modules," Journal of Photochemistry and Photobiology A, vol. 164, no. 1-3, pp. 203-207, 2004.

[12] P. Wang, S. M. Zakeeruddin, J. E. Moser, M. K. Nazeeruddin, T. Sekiguchi, and M. Grätzel, "A stable quasi-solid-state dyesensitized solar cell with an amphiphilic ruthenium sensitizer and polymer gel electrolyte," Nature Materials, vol. 2, no. 6, pp. 402-407, 2003.

[13] H. G. Agrell, J. Lindgren, and A. Hagfeldt, "Degradation mechanisms in a dye-sensitized solar cell studied by UV-VIS and IR spectroscopy," Solar Energy, vol. 75, no. 2, pp. 169-180, 2003.

[14] P. J. Sebastián, A. Olea, J. Campos, J. A. Toledo, and S. A. Gamboa, "Temperature dependence and the oscillatory behavior of the opto-electronic properties of a dye-sensitized nanocrystalline $\mathrm{TiO}_{2}$ solar cell," Solar Energy Materials and Solar Cells, vol. 81, no. 3, pp. 349-361, 2004.

[15] K. Lobato and L. M. Peter, "Direct measurement of the temperature coefficient of the electron quasi-Fermi level in dye-sensitized nanocrystalline solar cells using a titanium sensor electrode," The Journal of Physical Chemistry B, vol. 110, no. 43, pp. 21920-21923, 2006.

[16] M. Dürr, A. Yasuda, and G. Nelles, "On the origin of increased open circuit voltage of dye-sensitized solar cells using 4-tertbutyl pyridine as additive to the electrolyte," Applied Physics Letters, vol. 89, no. 6, Article ID 061110, 3 pages, 2006.

[17] H. J. Snaith, L. Schmidt-Mende, M. Grätzel, and M. Chiesa, "Light intensity, temperature, and thickness dependence of the open-circuit voltage in solid-state dye-sensitized solar cells," Physical Review B, vol. 74, no. 4, Article ID 045306, 6 pages, 2006.

[18] L. M. Peter, A. B. Walker, G. Boschloo, and A. Hagfeldt, "Interpretation of apparent activation energies for electron transport in dye-sensitized nanocrystalline solar cells," The Journal of Physical Chemistry B, vol. 110, no. 28, pp. 1369413699, 2006.

[19] H. G. Agrell, G. Boschloo, and A. Hagfeldt, "Conductivity studies of nanostructured $\mathrm{TiO}_{2}$ films permeated with electrolyte," The Journal of Physical Chemistry B, vol. 108, no. 33, pp. 12388-12396, 2004.

[20] G. Boschloo and A. Hagfeldt, "Activation energy of electron transport in dye-sensitized $\mathrm{TiO}_{2}$ solar cells," The Journal of Physical Chemistry B, vol. 109, no. 24, pp. 12093-12098, 2005.

[21] B. C. O'Regan and J. R. Durrant, "Calculation of activation energies for transport and recombination in mesoporous $\mathrm{TiO}_{2}$ /dye/electrolyte films-taking into account surface charge shifts with temperature," The Journal of Physical Chemistry B, vol. 110, no. 17, pp. 8544-8547, 2006.

[22] Q. Wang, J.-E. Moser, and M. Grätzel, "Electrochemical impedance spectroscopic analysis of dye-sensitized solar cells," The Journal of Physical Chemistry B, vol. 109, no. 31, pp. 14945-14953, 2005.

[23] R. Kern, R. Sastrawan, J. Ferber, R. Stangl, and J. Luther, "Modeling and interpretation of electrical impedance spectra of dye solar cells operated under open-circuit conditions," Electrochimica Acta, vol. 47, no. 26, pp. 4213-4225, 2002. 
[24] F. Fabregat-Santiago, J. Bisquert, G. Garcia-Belmonte, G. Boschloo, and A. Hagfeldt, "Influence of electrolyte in transport and recombination in dye-sensitized solar cells studied by impedance spectroscopy," Solar Energy Materials and Solar Cells, vol. 87, no. 1-4, pp. 117-131, 2005.

[25] J. Bisquert, G. Garcia-Belmonte, F. Fabregat-Santiago, N. S. Ferriols, P. Bogdanoff, and E. C. Pereira, "Doubling exponent models for the analysis of porous film electrodes by impedance. relaxation of $\mathrm{TiO}_{2}$ nanoporous in aqueous solution," The Journal of Physical Chemistry B, vol. 104, no. 10, pp. 2287-2298, 2000.

[26] J. Bisquert, G. Garcia-Belmonte, F. Fabregat-Santiago, and A. Compte, "Anomalous transport effects in the impedance of porous film electrodes," Electrochemistry Communications, vol. 1, no. 9, pp. 429-435, 1999.

[27] J. Bisquert, "Influence of the boundaries in the impedance of porous film electrodes," Physical Chemistry Chemical Physics, vol. 2, no. 18, pp. 4185-4192, 2000.

[28] T. Hoshikawa, T. Ikebe, R. Kikuchi, and K. Eguchi, "Effects of electrolyte in dye-sensitized solar cells and evaluation by impedance spectroscopy," Electrochimica Acta, vol. 51, no. 25, pp. 5286-5294, 2006.

[29] M. Adachi, M. Sakamoto, J. Jiu, Y. Ogata, and S. Isoda, “Determination of parameters of electron transport in dye-sensitized solar cells using electrochemical impedance spectroscopy," The Journal of Physical Chemistry B, vol. 110, no. 28, pp. 1387213880, 2006.

[30] T. Hoshikawa, R. Kikuchi, and K. Eguchi, "Impedance analysis for dye-sensitized solar cells with a reference electrode," The Journal of Electroanalytical Chemistry, vol. 588, no. 1, pp. 5967, 2006.

[31] T. Hoshikawa, M. Yamada, R. Kikuchi, and K. Eguchi, "Impedance analysis of internal resistance affecting the photoelectrochemical performance of dye-sensitized solar cells," Journal of the Electrochemical Society, vol. 152, no. 2, pp. E68E73, 2005.

[32] C. Longo, A. F. Nogueira, M.-A. De Paoli, and H. Cachet, "Solid-state and flexible dye-sensitized $\mathrm{TiO}_{2}$ solar cells: a study by electrochemical impedance spectroscopy," The Journal of Physical Chemistry B, vol. 106, no. 23, pp. 5925-5930, 2002.

[33] L. Han, N. Koide, Y. Chiba, A. Islam, and T. Mitate, "Modeling of an equivalent circuit for dye-sensitized solar cells: improvement of efficiency of dye-sensitized solar cells by reducing internal resistance," Comptes Rendus Chimie, vol. 9, no. 5-6, pp. 645-651, 2006.

[34] C. Shi, S. Dai, K. Wang, et al., "Influence of various cations on redox behavior of $\mathrm{I}^{-}$and $\mathrm{I}_{3}^{-}$and comparison between $\mathrm{KI}$ complex with 18-crown-6 and 1,2-dimethyl-3-propylimidazolium iodide in dye-sensitized solar cells," Electrochimica Acta, vol. 50, no. 13, pp. 2597-2602, 2005.

[35] Q. Wang, S. Ito, M. Grätzel, et al., "Characteristics of high efficiency dye-sensitized solar cells," The Journal of Physical Chemistry B, vol. 110, no. 50, pp. 25210-25221, 2006.

[36] F. Fabregat-Santiago, J. Bisquert, E. Palomares, et al., "Correlation between photovoltaic performance and impedance spectroscopy of dye-sensitized solar cells based on ionic liquids," The Journal of Physical Chemistry C, vol. 111, no. 17, pp. 6550-6560, 2007.

[37] K. Miettunen, J. Halme, M. Toivola, and P. Lund, "Initial performance of dye solar cells on stainless steel substrates," The Journal of Physical Chemistry C, vol. 112, no. 10, pp. 40114017, 2008.

[38] M. Toivola, L. Peltokorpi, J. Halme, and P. Lund, "Regenerative effects by temperature variations in dye-sensitized solar cells,"
Solar Energy Materials and Solar Cells, vol. 91, no. 18, pp. 1733-1742, 2007.

[39] M. Toivola, F. Ahlskog, and P. Lund, "Industrial sheet metals for nanocrystalline dye-sensitized solar cell structures," Solar Energy Materials and Solar Cells, vol. 90, no. 17, pp. 28812893, 2006.

[40] P. Wang, S. M. Zakeeruddin, and M. Grätzel, "Solidifying liquid electrolytes with fluorine polymer and silica nanoparticles for quasi-solid dye-sensitized solar cells," Journal of Fluorine Chemistry, vol. 125, no. 8, pp. 1241-1245, 2004.

[41] J. R. Macdonald, Impedance Spectroscopy, Wiley, New York, NY, USA, 1987. 


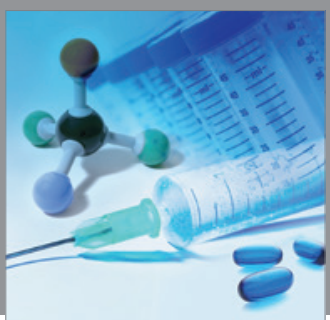

International Journal of

Medicinal Chemistry

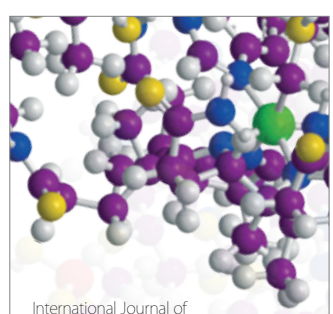

Carbohydrate Chemistry

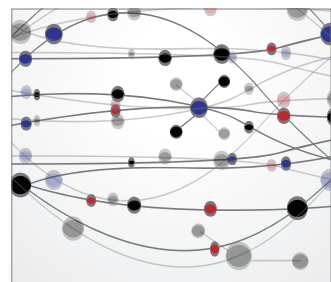

The Scientific World Journal
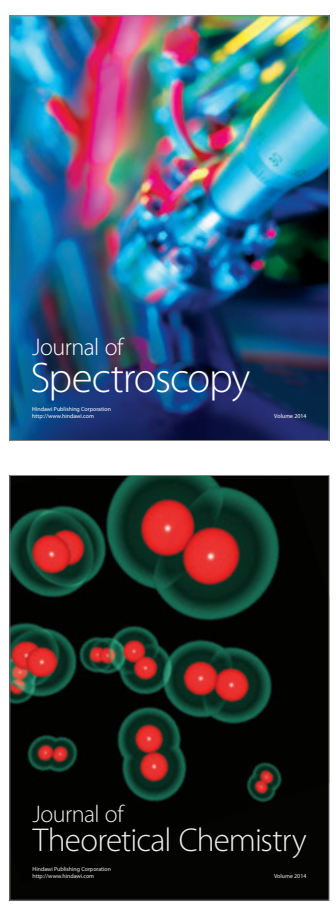
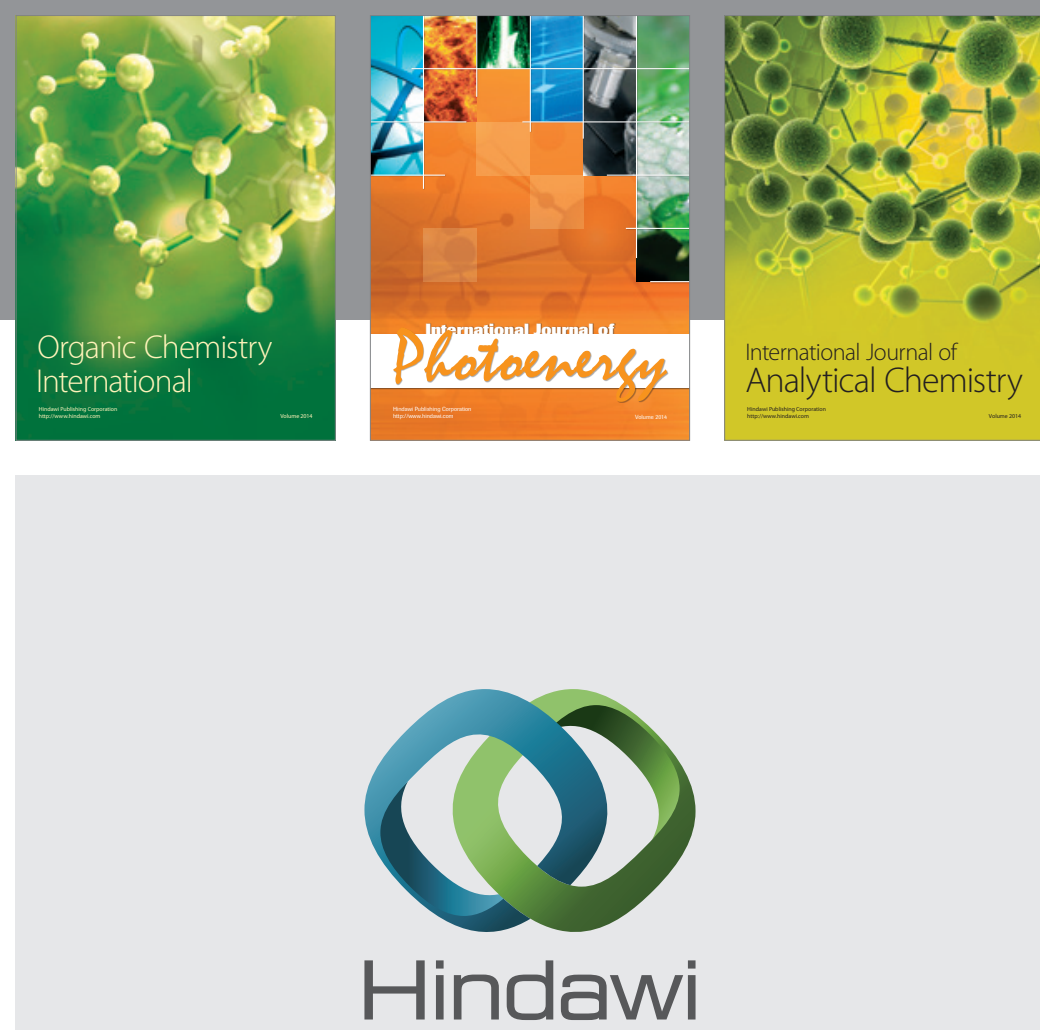

Submit your manuscripts at

http://www.hindawi.com
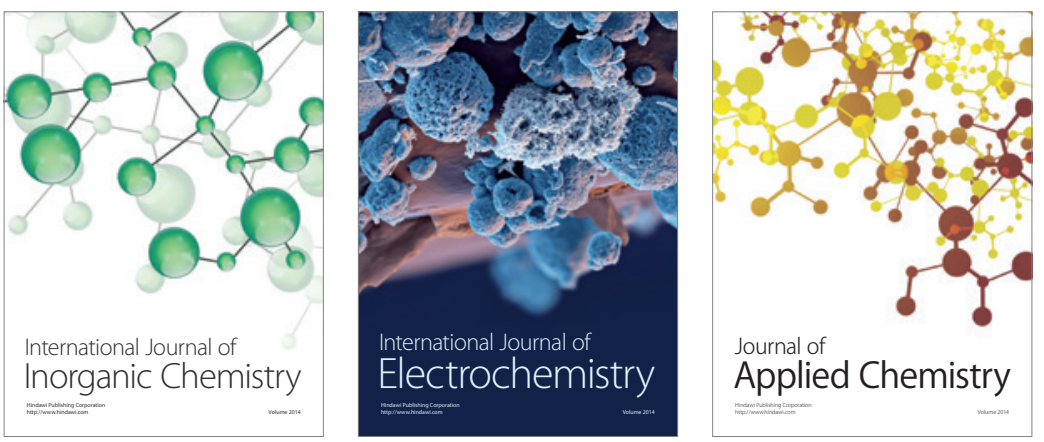

Journal of

Applied Chemistry
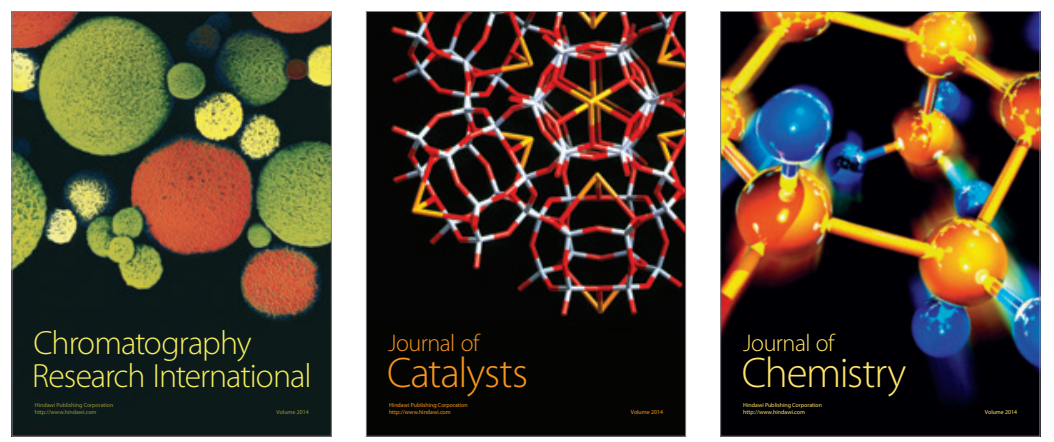
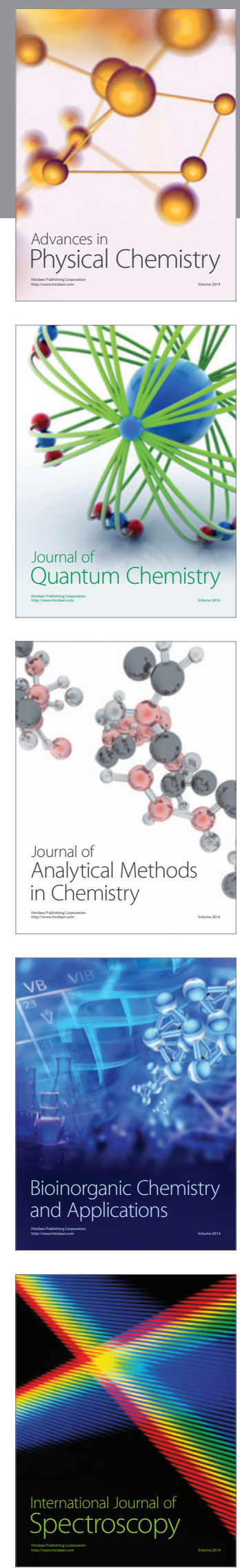